\title{
BONEs not CATs attract DOGs: Semantic context effects for picture naming in the lesioned language network.
}

Danièle Pino ${ }^{1,2}$, Andreas Mädebach ${ }^{3}$, Jörg D. Jescheniak ${ }^{3}$, Frank Regenbrecht ${ }^{1,2}$, and Hellmuth Obrig ${ }^{1,2}$

${ }^{1}$ Clinic for Cognitive Neurology, University Hospital / Faculty of Medicine, Leipzig University

${ }^{2}$ Max-Planck-Institute for Human Cognitive and Brain Sciences, Leipzig; Germany

${ }^{3}$ Department of Psychology, Leipzig University; Germany

Short Title:

Semantic context effects after brain lesion.

Correspondence to:

Danièle Pino, MA / Hellmuth Obrig MD, Prof. Dr. med.;

Clinic for Cognitive Neurology, University Hospital Leipzig; Liebigstraße 16;

Max-Planck-Institute for Human Cognitive and Brain Sciences, Stephanstraße 1a; 04103 Leipzig, Germany.

T: +49(0)341-9724-24963; F:-24989; email: pino@cbs.mpg.de / obrig@cbs.mpg.de 


\section{Abstract}

The breakdown of rapid and accurate retrieval of words is a hallmark of aphasic speech and a prime target of therapeutic intervention. Complementary, psycho- and neurolinguistic research have developed a spectrum of models, how and by which neuronal network uncompromised speakers can rely on remarkable lexical retrieval capacities. Motivated by both lines of research we invited 32 participants with a chronic left hemispheric brain lesion to name pictures in the presence of distractor words. This picture-word-interference (PWI) paradigm is widely used in psycho- and neurolinguistic research.

We find that also after brain lesion categorically related words $\left(\mathrm{CAT} \rightarrow[\mathrm{dog}]^{\text {picture }}\right.$ ) impede naming, while a associatively related words $\left(\mathrm{BONE} \rightarrow[\mathrm{dog}]^{\text {picture }}\right)$ ease access. The effects largely affecting latencies in neurotypical populations, are reproduced for error rate in our participants with lesions in the language network. Unsurprisingly, overall naming abilities varied greatly across patients. Notably, however, the two effects (categorical interference / associative facilitation) dissociate between participants. Correlating performance with lesion patterns we moreover find robust evidence for a dissociation of brain areas affording different aspects of the task: (i) lesions in the left MTG deteriorate overall naming, confirming previous work; more notably (ii) lesions comprising the inferior frontal hub of the language-network increase interference effect for the categorical condition; on the contrary (iii) lesions to the midto-posterior temporal hub increase the facilitatory effect for the associative condition on error rates.

The findings are of relevance to the understanding of the functional anatomy of word-retrieval. Although experimental in nature the data moreover suggest that depending on lesion site different strategies may be required in the rehabilitation of aphasic word retrieval deficits.

Keywords: Semantic Interference, Picture word interference paradigm, Aphasia, Stroke: imaging, Cortical plasticity, Stroke: rehabilitation, Temporal lobe, Frontal lobe 


\section{Introduction}

Rapid and accurate lexical retrieval is a prerequisite for fluent language production. The ease by which we choose the correct word from the large mental lexicon is, however, brittle: errors occur in uncompromised speakers, increase with normal ageing (Meinzer et al., 2009, Bortfeld et al., 2001) and may be an early sign of imminent cognitive impairment (Mueller et al., 2017). Moreover, word finding difficulties are the most common deficits persisting in aphasia, even if residual (Kohn and Goodglass, 1985). Research on the mechanisms underlying lexical retrieval has identified a number of factors modulating its speed and accuracy. Unsurprisingly, lexical frequency is relevant: retrieval of the word 'flamingo' is harder than 'duck'. However, in the sentence 'On the safari she most liked the sight of a lake crowded by pink__ ' the frequency advantage for 'duck' is overridden by context. It seems intuitive that a specific semantic context should ease retrieval of semantically related words. However, there is abundant evidence for semantic-categorically related context words to interfere with the naming response of the target $\left(\right.$ cat $^{\text {context }} \rightarrow$ dog $\left.^{\text {target }}\right)$. In fact, competition within a lexical cohort is a key feature of a classical model for word production (Levelt et al., 1999, Roelofs, 1992). It posits that successful retrieval of a member of the cohort (e.g. 'animals') is more time consuming and error prone, the higher the activation of other category-members. This may result from a relative selection threshold to be surpassed (e.g. Levelt et al., 1999)) or from lateral inhibition between co-activated representations (e.g. Harley, 1993)). Therefore, retrieval of 'dog' is hampered by the coactivation of 'cat' but not 'car'. Moreover, 'cat' is the more likely erroneous output, when the intended word 'dog' cannot be retrieved, as evidenced by sematic errors in aphasic speech (Schwartz, 2014).

Competition in word production is supported by numerous studies demonstrating semantic interference from categorically related contexts. Three principal designs with several variations have been used. Blocked-Cyclic and Continuous Naming require naming of pictures in 
succession. Interference is evidenced in that reoccurrence of a specific category (e.g. animals) increases naming latency for a successive exemplar of that category in Continuous Naming (e.g. Oppenheim et al., 2010)). Similarly, blocks with categorically related items presented repeatedly slow naming compared to unrelated item blocks (e.g. Kroll and Stewart, 1994, Damian et al., 2001). The other widely used paradigm is the Stroop-like picture word interference paradigm (PWI) in which speed and accuracy of picture naming is assessed in the context of a distractor word (Glaser and Dungelhoff, 1984) ${ }^{1}$. Again categorically related words interfere with the naming of the target picture when compared to a semantically unrelated word. Conversely, in PWI paradigms associatively related context words (bone $\mathrm{b}^{\text {context }} \rightarrow \operatorname{dog}^{\text {target }}$ ) have been shown to facilitate naming (La Heij et al., 1990). Neurotypical participants name the picture of a dog faster when the word 'bone' has been presented prior to the picture, when compared to an unrelated word.

The locus at which interference impacts on production is controversial. In the above model the lexical level of word production is considered to be sensitive to interference (Roelofs, 1992, La Heij, 1988, Damian and Bowers, 2003), while at the conceptual level semantic relatedness elicits facilitation (Bloem and La Heij, 2003). Since verbal competitors induce facilitation when presented $400 \mathrm{~ms}$ prior to the target, the model additionally posits that lexical competition decays faster than conceptual facilitation (Bloem et al., 2004). However, in word-picture matching tasks, not requiring lexicalization of the competitors, semantic interference effects have been shown also in neurotypical participants (Harvey and Schnur, 2016, Campanella and Shallice, 2011). This suggests a prelexical locus of interference in the semantic system. To explain semantic interference in continuous naming and blocked cyclic naming paradigms incremental learning mechanisms, strengthening the connection between semantic and lexical representations have been suggested (Belke and Stielow, 2013, Oppenheim et al., 2010). To

\footnotetext{
${ }^{1}$ The design resembles Stroop paradigms requiring the suppression of a written distractor. For a discussion on the similarity and differences between tasks, see Starreveld \& La Heij 2017.
} 
complicate matters, semantic interference in the PWI task has also been ascribed to control processes operating at postlexical stages of word production (Finkbeiner and Caramazza, 2006, Mahon et al., 2007). One motivation for this is the finding that frequency effects of the distractor words are inverse to what is expected for lexical competition² (Dhooge and Hartsuiker, 2011, cf. Roelofs et al., 2011). Models postulating a lexical versus postlexical level of interference may not be mutually exclusive. An elegant fMRI study demonstrated differential effects of distractor word's frequency versus its age-of-acquisition. While frequency modulated brain activation in areas putatively affording postlexical processes (bilateral premotor / left pSTG/pMTG) age-of-acquisition modulated activation in areas assumed to house the lexicon (mostly left mid-MTG). Thus interference at different stages of the naming process may be assumed (de Zubicaray et al., 2012).

Another controversial issue regarding semantic interference effects pertains to the question how activation of a lexical cohort, competition between cohort members and selection of the target interact. Differences between high versus low demand scenarios and varying task requirements have provided evidence for competitive (Roelofs, 1992) but also non-competitive (Mahon et al., 2007) accounts. Of special relevance to the present study, this issue extends to the question in how far lesions to the language network can differentially alter activation and selection processes resulting in non-fluent and/or erroneous production in people with aphasia (Nozari and Hepner, 2019, Anders et al., 2017, Ries et al., 2019). Beyond their role in shaping models of word production, semantic context effects during picture naming are of relevance to interventions in people with aphasia, since various confrontational naming schemes may be considered a pillar of Speech-and-Language-Therapy (SLT, e.g. Conroy et al., 2018).

\footnotetext{
${ }^{2}$ High frequency (HF) show smaller interference effects when compared to low frequency (LF) distractors. This contradicts the lexical competition account in that higher intrinsic activation level of HF-words should increase interference.
} 
To address these issues we here investigate in how far facilitation and interference can be elicited in the lesioned language network and whether either process relates to dissociable processes corresponding to dissociable 'hubs' in the neuronal network affording confrontational naming. Using a well-controlled set of word-picture pairs (Henseler et al., 2014) in participants with circumscribed chronic lesions in the left-hemispheric language network, we hypothesized that interference and facilitation effects are respectively modulated by lesions in distinct parts of the network. Following a parsimonious approach to levels of speech production (Nozari, 2021) we focus on two stages of lexical retrieval: activation of the lexical cohort and selection of the lexical entry. We hypothesize lesions in areas housing the lexicon to alter lexical (cohort) activation, which should differ from the effect of lesions in brain areas affording lexical selection. While it is uncontroversial, that a distributed network supports lexical retrieval, evidence from neurotypical participants (Binder et al., 2009, Maess et al., 2002, de Zubicaray et al., 2001) and lesion studies (Schwartz et al., 2009, Baldo et al., 2013) converges on lexical activation to rely on the left middle/inferior temporal gyrus (MTG/ITG). Regarding lexicosemantic selection processes especially under higher demand conditions frontal areas including the left IFG have been suggested of relevance (Schnur et al., 2009, Abel et al., 2009, Badre et al., 2005). However, the role of left frontal areas in semantic interference is more controversial. For example participants with lesions of the lateral prefrontal cortex (PFC) showed no increase in interference for semantic cohort distractors in a PWI paradigm, while overall lexical interference (all lexical vs. non-lexical distractors) was augmented (Piai et al., 2015, Piai and Knight, 2018).

The current work is the first lesion study to directly compare categorical interference and associative facilitation in a PWI paradigm in a larger group of patients; therefore functional anatomic hypotheses remain tentative. We predict (i) lesions in frontal areas relevant for selection to increase interference effects elicited by categorically related primes (Anders et al., 2017) while (ii) lesions in areas housing the lexicon should reduce target and cohort activation. 
Reduced cohort and target activation may increase categorical interference due to "noisy access to lexical representations" (Harvey and Schnur, 2015). However, associative priming may conversely become more relevant supporting the selection process, since overt behavioral effects represent the net of underlying competitive and facilitatory processes (Abdel Rahman and Melinger, 2019, van Scherpenberg et al., 2020). In sum we expect modulations caused by distinct lesion patterns to interact differentially with lexical competition, prevailing in categorical distractors $\left(\mathrm{CAT} \rightarrow[\mathrm{dog}]^{\text {picture }}\right)$, and with associative facilitation when the distractor word and the to-be-named picture share an associative semantic relation $\left(\mathrm{BONE} \rightarrow[\mathrm{dog}]^{\text {picture }}\right)$.

\section{Material and Methods}

\subsection{Participants}

32 patients with a chronic, acquired left hemispheric brain lesion participated in the study (age: mean $\pm S D=51.9 \pm 11.51$ years, [range: $25-76$ ], 16 females). The aetiologies comprised vascular but also other CNS-diseases leading to a circumscribed brain lesion (see supplemental table ST1). Patients were selected from a data bank of the Clinic for Cognitive Neurology (University-Hospital Leipzig) and the Max-Planck-Institute for Human Cognitive and Brain Sciences. Exclusion criteria were additional right-hemispheric lesions and severe overall cognitive impairment. Additional cognitive impairments were rated based on a detailed assessment of experienced neuropsychologists to exclude severe attentional, overarching memory and executive deficits. Aphasia was diagnosed based on the standard German assessment battery (Aachener Aphasie Test, AAT, Huber et al., 1984); patients with residual or no aphasia at the time of inclusion had all been documented to show an aphasic deficit at an earlier stage of the disease (supplemental table ST1 for demographic and clinical information). Regarding language competence, severe naming disorder (subtest naming AAT, PR $<32$ ), 
dyslexia (subtest written language AAT, PR $<30$ ) or inability to understand the instructions precluded from participation.

In all patients brain imaging allowed for lesion delineation. In 30 patients a high-resolution structural MRI acquired at the MPI-CBS was available (3T Scanner; T1 MP-Rage/mdeft with $1 \mathrm{~mm}^{3}$ isovoxel; FLAIR image as reference). In two patients clinically motivated MRIs, with a lesser resolution were used. All patients gave informed consent according to the Declaration of Helsinki. The experiment was approved by the local ethic committee of the University of Leipzig (Nr.:144/18-ek, 13.4.2018).

\subsection{Stimuli}

For the PWI-task patients were asked to name a target picture as fast and accurate as possible. A visual distractor word was presented shortly prior to the to-be-named target picture. The semantic relation between word and picture-target differed, resulting in 4 conditions:

(1) ASS $^{\text {related }}$ - associatively related pairs (e.g., Knochen [bone] - Hund [dog])

(2) $\mathrm{CAT}^{\text {related }}$ - categorically related pairs (e.g., Kirsche [cherry] - Apfel [apple])

(3) $\mathrm{ASS}^{\text {unrelated }}$ - unrelated controls for $\mathrm{ASS}^{\text {related }}$ (e.g., Reiter [horseman] - Hund [dog])

(4) $\mathrm{CAT}^{\text {unrelated }}$ - unrelated controls for CAT ${ }^{\text {related }}$ (e.g., Wippe [seesaw] - Apfel [apple]).

There was no overlap of the material (words and pictures) between the associative and categorical conditions. However, the control conditions, (ASS $\left.{ }^{\text {unrelated}} / \mathrm{CAT}^{\text {unrelated }}\right)$ were created by rearranging the respective set of $\mathrm{ASS}^{\text {related }}$ and $\mathrm{CAT}^{\text {related }}$, abolishing the relationship between picture and word. A fixed delay of $-300 \mathrm{~ms}$ between word and picture presentation (stimulusonset-asynchrony, SOA) was used for the associative conditions. For the categorical conditions an SOA of -100 ms was used (Figure 1A). These SOAs as well as the two item sets are the same as in Henseler et al. (2014) and were chosen to maximize facilitation and interference effects respectively. 
The stimulus set comprised 88 black-and-white drawings of everyday objects (40 for categorical, 40 for associative condition, 8 practice items) and the assigned distractor words (set identical to study in neurotypical participants, Henseler et al., 2014). All pictures had high naming agreement in neurotypical participants. Picture sets used in the associative and categorical conditions were matched for linguistic parameters influencing speed of picture naming and distractor recognition, including word length, lemma frequency, name-, imageagreement, visual complexity, familiarity, number of syllables, and graphemes (Henseler et al., 2014, table 1, p.1406). Associatively related distractor words were selected on the basis of an association data base (Melinger and Weber, 2006). Categorically related distractor words were drawn from the same semantic category as the picture names.

\subsection{Procedure}

The experimental session comprised: consent and instruction, familiarization, training, main experiment, and assessment of reading comprehension.

During familiarization participants named all pictures twice, first in the presence of its name written below the picture, then in isolation. To introduce the PWI paradigm, patients were asked to name eight practice items in the presence of unrelated distractors. The main experiment required the naming of 80 target pictures. Each picture was named twice: once in the presence of an associatively or categorically related distractor word and once with an unrelated distractor word. To avoid predictions about the following items based on the differing SOAs ASS and CAT conditions were blocked, and presented in blocks of 21 items. The $1^{\text {st }}$ item of each block did not enter analyses since it was used as practice item. ASS and CAT blocks alternated, with their sequence being balanced across participants. Within the eight blocks (four associative/ four categorical) related and unrelated pairs were pseudorandomized. No picture appeared twice within the same block. To avoid sequence effects, related and unrelated conditions for each target picture were counterbalanced across participants. Upon request participants were allowed 
pauses between blocks. In all, there were 168 experimental trials per patient (including the eight practice items, one at the beginning of each block).

Because reading comprehension of the distractor words is mandatory for the paradigm to work, the ability to access the semantic system via reading was asessed after the main experiment in a word-picture-matching task using the experimental picture set. Despite the lesions in the language network all participants performed at ceiling achieving over $98 \%$ correct reactions.

Each trial started with the presentation of a fixation cross for $700 \mathrm{~ms}$ followed by a blank screen for $2000 \mathrm{~ms}$. Next the distractor word appeared in the centre of the screen (font: Arial, bold, upper-/ lower-case letters according to German orthography). Picture presentation followed after $100 \mathrm{~ms}$ for categorical and $300 \mathrm{~ms}$ for associative conditions. The distractor word remained in the centre of the target picture $(7 \times 7 \mathrm{~cm})$. Presentation ended $3000 \mathrm{~ms}$ after the voicekey had been triggered. The response interval started at picture onset, time-out for the response was 10 seconds. The trial structure is illustrated in Figure $\mathbf{1 A}$.

The paradigm was implemented on DMDX (Version 5.134). Patients were seated in front of a TFT monitor (Samsung Sync Master 2233R2, 22 inch, 1680 x 1050 pixels) with a viewing distance of $\sim 100 \mathrm{~cm}$. Naming latencies were collected on-line by using a SONY Condenser C48 microphone and a Nesubox-Lite hardware voicekey. In addition, the experimental sessions were digitally recorded to allow for an off-line validation of speech onset measurements.
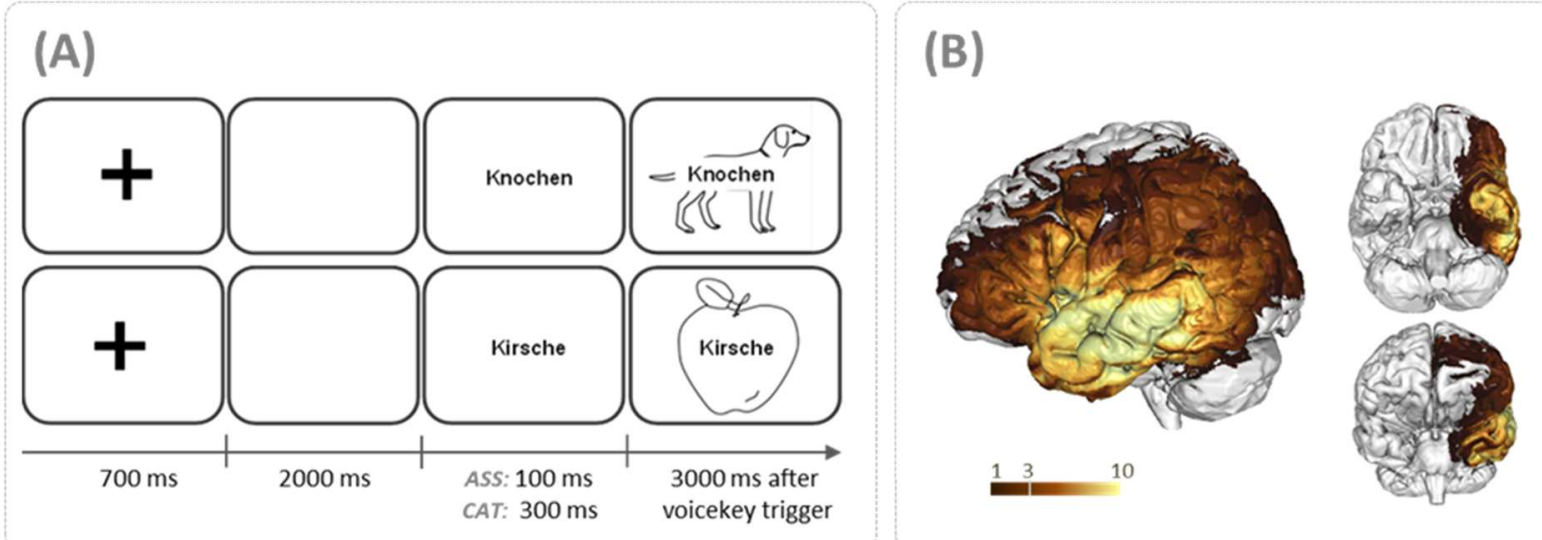
Figure 1: (A) Picture-word Interference (PWI) paradigm. A fixation cross was followed by the distractor word in the associative condition (ASS; SOA of $300 \mathrm{~ms}$, 'Knochen' engl.: bone) and the categorical condition (CAT; SOA of $100 \mathrm{~ms}$, 'Kirsche' engl.: cherry). The distractor word remained on the screen during target presentation. After the voicekey was triggered the pictuire remained on the screen fpor another $3 \mathrm{~s}$. Time-out for the voice key trigger was $10 \mathrm{~s}$. The time window to initiate a response was maximally $10 \mathrm{sec}$. (B) Lesion overlay map of the 32 patients. Coloured areas are lesioned in at least one patient. Lesion-behaviour analyses were performed in areas in which at least 3 lesions overlapped. A more detailed representation of the lesion coverage is supplied in Supplementary Figure SF1.

\subsection{Statistical analyses}

Naming latencies (LAT) and error rates (ERR) were analysed separately. For error analysis the following reactions were coded as errors and discarded from the analysis of latencies: (1) no response, (2) self-corrections, (3) semantic substitutions/paraphasias, (4) phonological substitutions/paraphasias, and (5) reading of the distractor word. Because a number of patients showed word finding difficulties as indicated by filled/unfilled pauses and search behaviour on initial phonemes or syllables due to apraxia of speech or a phonological disorder, the latency analyses required a finer grained off-line analysis. Using the audio recordings and the program Check Vocal (Protopas, 2007), we identified the first complete utterance and used it for adjusting the response-onset measurement. Therefore, hesitations were captured as prolonged naming latency rather than contributing to the error analysis. If an erroneous reaction was interrupted to then produce a correct reaction, this was considered an error. In case of phonetic errors due to dysarthria or apraxia of speech, a reaction was considered correct if at least $75 \%$ of the phonemes were correct. For the analyses, these offline determined latencies and errors were used.

Behavioral data (LAT, ERR) were analyzed separately for the associate and categorical conditions. We do not report an overall analysis of relatedness (all related vs. all unrelated items) because the factor "type of relation" (TYPE in the following) was confounded with SOA and with the use of different item sets. To compare associatively / categorically related and their 
corresponding unrelated conditions two paired t-tests were conducted ( $95 \%$ confidence interval). Statistical analyses were performed in R (3.3.2).

If associative facilitation and categorical interference can be demonstrated on the group level a central question is whether the two effects dissociate across participants. Therefore we performed several correlation analyses between the effects for overall performance and associative facilitation / semantic interference effects using Pearson's correlation analysis. Moreover, we argue that if the two processes are (partially) independent they may rely on the integrity of partially discernible anatomical hubs in the language network. Therefore, we performed a lesion-behaviour analysis as detailed next.

\subsection{Lesion-behaviour analyses}

For lesion-behavior analyses, lesions were manually delineated on each slice of the T1-images using MRIcron (Rorden and Brett, 2000). FLAIR-images served as a reference. For normalization and transformation of the lesion masks into standard stereotactic space (MNI) the 'clinical toolbox' (www.nitrc.org/projects/clinicaltbx/) in SPM8 (fil.ion.ucl.ac.uk/spm) was used. It applies the unified segmentation approach (Ashburner and Friston, 2005) restricting estimation of normalization parameters to healthy tissue (Brett et al., 2001). Because the resolution of the clinical MRI-images (in 2 participants) was lower than the standard $1 \mathrm{~mm}^{3}$ isovoxel resolution of the in-house MRIs, the former were interpolated to $1 \mathrm{~mm}^{3}$ images. Prior to subsequent analysis steps normalizations were checked, and compared to the original images. The image analysis was performed by a neurologist experienced in clinical and experimental image analysis (HO). If lesion delineation was debatable a colleague form the Department of Neuroradiology was consulted. A lesion overlay map of the 32 patients is shown in Figure $\mathbf{1 B}$.

To assess correlations between behavior and lesion pattern the voxel-based lesion symptom software developed by Stephen Wilson was used (https://langneurosci.mc.vanderbilt.edu/ 
resources.html, (Bates et al., 2003, adaptation in communication with S. Wilson) ${ }^{3}$. Based on the binary lesion maps, t-statistics determine whether a voxel correlates in a statistically significant way with performance in a behavioral measure. In other words, t-tests comparing performance between participants with versus without a lesion indicate 'relevance' of this voxel for the respective test.

To tackle the issue of multiple comparisons we used the permutation method (with 2,000 permutations) to correct for false positives. We report cluster-based correction, meaning that after a statistical base-map is generated, clusters surviving the threshold are corrected for multiple comparisons yielding a corrected $p$ at the cluster level. For the first step ( $p$ of base) we used the threshold of $p<0.001$ unless stated otherwise. Clusters are reported if they survived correction at a $p<0.05$. Another issue is correction for volume size. For patients with large lesions, lesser performance may reflect lesser overall performance due to lesions in other regions. This can be addressed by introducing lesion size as a covariate. However, lesion size is a rough estimate of the contribution of other areas to the voxel tested and may produce false positives. Therefore, we performed all analyses with and without lesion size as a covariate. For all results reported below we explicitly state whether lesion size was included or not.

Finally, lesion-symptom approaches generally assume that performance deteriorates with a lesion while inverse correlations (i.e. 'improvement' in response to a lesion) are considered meaningless. In our paradigm this holds for the overall performance because more errors and longer response latencies can be expected in patients with more severe impairment. However, regarding semantic interference and associative facilitation it is conceivable that a lesion in two different brain areas may yield inverse effects. For example a lesion interfering with the retrieval of the categorical distractor would decrease interference while a lesion in an area

\footnotetext{
${ }^{3}$ We checked selected results by using the software by C. Rorden allowing for non-parametric statistics (BrunnerMunzel test). This yielded largely overlapping results. http://www.cabiatl.com/mricro/npm/; Rorden et al., 2007).
} 
affording lexical selection should increase interference. Therefore correlation analyses for the interference/ facilitation effects were performed in both directions (i.e., both lower and higher values could correlate with the lesion in a specific voxel).

Data availability: Pseudonymized data are available on request.

\section{Results}

\subsection{Group-level behavioural effects}

Categorically related words should decrease whereas associatively related words should enhance naming performance compared to unrelated words. Healthy volunteers largely perform at ceiling making latency the typical outcome measure. In patients with a language-related deficit, more errors are expected, therefore we analysed both parameters independently. The results are illustrated in Figure 2 and Table 1.

\begin{tabular}{ll|ccc|ccc}
\hline & & \multicolumn{3}{c|}{ LATencies [ms] } & \multicolumn{3}{c}{ ERRors } \\
\cline { 2 - 8 } & & mean & $S D$ & range & mean & $S D$ & range \\
\hline \multirow{2}{*}{ ASS } & rel & $\mathbf{1 4 1 7}$ & 728.6 & $676-3721$ & $\mathbf{1 . 4}$ & 2.09 & $0-9$ \\
\cline { 2 - 8 } & unrel & $\mathbf{1 3 9 9}$ & 691.7 & $706-3830$ & $\mathbf{1 . 9}$ & 2.67 & $0-12$ \\
\cline { 2 - 8 } & $\Delta^{\text {rel-unrel }}$ & $\mathbf{1 8}$ & 152.8 & $-174-416$ & $-\mathbf{0 . 5}$ & 1.14 & $-4-1$ \\
\hline \multirow{2}{*}{ CAT } & rel & $\mathbf{1 5 9 1}$ & 685.4 & $\mathbf{7 4 7 - 3 6 3 5}$ & $\mathbf{3 . 4}$ & 3.92 & $0-18$ \\
\cline { 2 - 8 } & unrel & $\mathbf{1 4 6 8}$ & 696.7 & $676-3750$ & $\mathbf{2 . 4}$ & 3.88 & $0-16$ \\
\cline { 2 - 8 } & $\Delta^{\text {rel-unrel }}$ & $\mathbf{1 2 4}$ & 166.8 & $-211-502$ & $\mathbf{1 . 0}$ & 1.77 & $-2-7$ \\
\hline
\end{tabular}

Table 1: Mean naming latencies (LAT in $\mathrm{ms}$ ) and mean number of errors (ERR in whole numbers) and corresponding standard deviations (SD) and ranges. ASS: associatively related condition; CAT: categorically

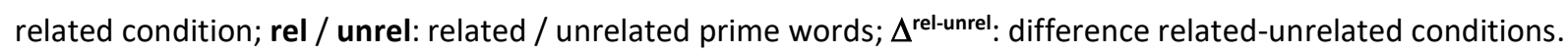

Regarding the effects of categorical and associative contexts paired, two-sided t-tests confirmed significantly longer naming latencies in the categorically related compared to the corresponding unrelated condition $(t=4.193, d f=31, p=.0002)$. No significant difference was seen for naming latencies between the associatively related and the respective unrelated condition $(t=$ 
$0.677, d f=31, p=.5033)$. For error rates paired, 2-sided t-tests confirmed significantly lower error rates in the associatively related condition $(t=-2.647, d f=31, p=.013)$, and higher error rates in the categorically related condition $(t=3.298, d f=31, p=.002)$ compared to the respective unrelated conditions.

On the group level, patients thus showed the effects predicted by the work in healthy volunteers (Abel et al., 2009, Henseler et al., 2014): categorical relation elicited interference, while associative relation led to facilitation. Both effects were seen for the error-rate analysis, while latencies only showed the interference effect for the categorical relation.

Due to stricter error classification and significantly lower age in the neurotypical group reported by Henseler and colleagues $(\mathrm{n}=36$, mean age $=26.2$ years \pm 2.98 years, no TDCS-stimulation, i.e. 'sham'; Henseler et al., 2014), the formal statistical comparison between the patient-cohort of the present study and the neurotypical group examined with the identical material must be considered exploratory. Mixed 2x2 ANOVAs (GROUP x RELATEDNESS) were performed. Compared to the neurotypical cohort, patients showed higher error rates in the categorical condition (main effect of GROUP, $F(1,66)=6.442, \mathrm{p}<.001$; main effect of RELATEDNESS, $\mathrm{F}(1,66)=10.877, \mathrm{p}<.001 ;$ no interaction, $\mathrm{F}(1,66)=1.720, \mathrm{p}>.05)$ and a trend towards higher error rates in associative contexts (trend GROUP, $F(1,66)=3.013, p=.087$; main effect of RELATEDNESS, $\mathrm{F}(1,66)=4.555, \mathrm{p}<.05$; no interaction, $\mathrm{F}(1,66)=2.420, \mathrm{p}>.05)$ despite more liberal error classification.

Patients showed higher reactions times compared to the neurotypical cohort in the associative condition (main effect of GROUP, $\mathrm{F}(1,66)=36.441, \mathrm{p}<.001$; no effect of RELATEDNESS, $\mathrm{F}(1,66)=0.031, \mathrm{p}=.860$; no interaction, $\mathrm{F}(1,66)=2.507, \mathrm{p}>.05)$ and in the categorical condition (main effect of GROUP, $\mathrm{F}(1,66)=46.505, \mathrm{p}<.001$; main effect of RELATEDNESS, $\mathrm{F}(1,66)=30.530, \mathrm{p}<.001$; significant interaction, $\mathrm{F}(1,66)=10.024, \mathrm{p}<.05$. The item analyses confirmed the results for error rates and reaction times. 


\subsection{Individual variance in performance}

Both parameters (LAT and ERR) greatly varied between patients, depending on severity of overall impairment and individual patholinguistic profile: LAT: $1468 \mathrm{~ms} \pm 691.4$ [701-3734] and ERR: $9.1 \pm 11.80$ [0-55] (mean $\pm S D$, [range]). Because inter-individual differences are by far larger than expected interference / facilitation effects, LAT and ERR strongly correlated across all conditions. Examples of correlations between related and respective unrelated conditions for LAT and ERR are shown in Figure $\mathbf{2 B}$. In sum, performance in one condition is highly predictable by overall performance and/or performance in any of the other conditions.
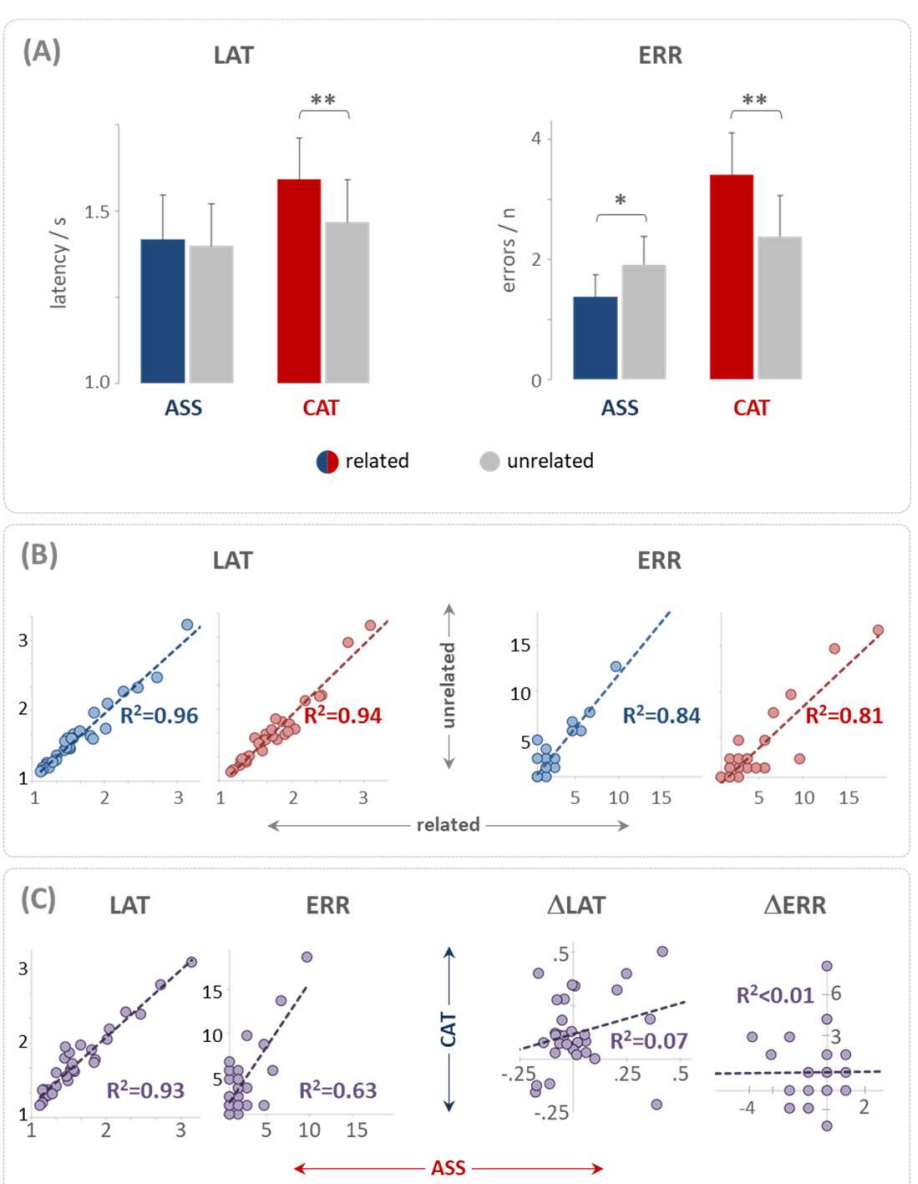

Figure 2: (A) Comparison between categorically and associatively related conditions (CAT, blue and ASS, red bars) and their resepective unrelated controls (grey bars). Categorically related words lead to longer naming latencies (LAT, left) and more errors (ERR, right). Associatively related words facilitated naming correctness (fewer errors) but did not decrease naming latency. Note that unrelated conditions (grey bars) involve different items, thus a direct comparison is not possible. ${ }^{*} p<.05, * * p<.01$, according to paired two-sided t-statistics. (B) Correlations between related ( $x$-axis) and unrelated conditions ( $y$-axis) (CAT, blue and ASS, red). In both outcome parameters (errors in whole numbers, ERR; latency in S, LAT) a strong correlation was seen indicating that the overall level of naming impairment is the major factor causing variance across the cohort. (C) Correlations between naming performance for categorically (CAT, $y$ axis) and associatively (ASS, $x$-axis) related items. While absolute values of ERR and LAT correlate strongly (left graphs, in absolute numbers/ seconds) indicating the major influence of overall naming impairment, the difference between

related and the respective unrelated conditions shows no or non-significant correlations (right graphs). This indicates that the size of the facilitatory/ inhibitory effect of the two conditions dissociates in patients (see Supplementary Figure SF2 for another visualisation of this dissociation between effects).

Our interest is how lesions in the language network modulate associative facilitation and semantic interference effects. Therefore, we quantified these effects by subtracting performance 
in the respective unrelated from associatively and categorically related items: $\Delta \mathrm{LAT}=\mathrm{LAT} T^{\text {related_}}-\mathrm{LAT} T^{\text {unrelated }}$ and $\Delta \mathrm{ERR}=\mathrm{ERR}^{\text {related_ERR }}{ }^{\text {unrelated }}$. Note that for both measures, negative (smaller) values indicate (more) facilitation while larger (positive) values indicate (more) inhibition of the naming response. Figure $2 C$ demonstrates that correlations between absolute performance for CAT and ASS are abolished when the difference values are used, indicating that the size of the effect in the categorical condition does not predict the size of the effect in the associative condition and vice versa. The dissociation between the effects is also illustrated in Supplementary Figure SF2.

\begin{tabular}{|c|c|c|c|c|c|c|c|c|c|c|c|c|}
\hline & $\begin{array}{l}\text { lesion } \\
\rightarrow\end{array}$ & $\begin{array}{c}\text { size } \\
{\left[\mathrm{cm}^{3}\right]}\end{array}$ & $\begin{array}{l}\boldsymbol{p} \text { of } \\
\text { base }\end{array}$ & $\begin{array}{c}p @ \\
\text { cluster }\end{array}$ & $\begin{array}{c}\max \\
\mathrm{T}\end{array}$ & $x$ & $\begin{array}{c}\text { MNI } \\
\mathrm{y}\end{array}$ & Z & aal & Harvard & BA & $\begin{array}{l}\text { Dia } \\
\text { Sph }\end{array}$ \\
\hline ERR $^{\text {ALL }}$ & $\uparrow$ & 10.80 & .001 & .042 & 9.9 & $\begin{array}{l}-65 \\
-51\end{array}$ & $\begin{array}{l}-17 \\
-53\end{array}$ & $\begin{array}{l}-25 \\
-5\end{array}$ & $\begin{array}{l}\text { ITG } \\
\text { ITG }\end{array}$ & $\begin{array}{c}\text { p MTG } \\
\text { t-occ MTG }\end{array}$ & $\begin{array}{l}20 \\
37\end{array}$ & - \\
\hline LAT $^{\text {MEAN }}$ & $\uparrow$ & 9.46 & .001 & .028 & 5.3 & $\begin{array}{l}-55 \\
-51\end{array}$ & $\begin{array}{l}-44 \\
-12\end{array}$ & $\begin{array}{l}-10 \\
-18\end{array}$ & $\begin{array}{l}\text { MTG } \\
\text { MTG }\end{array}$ & $\begin{array}{c}\text { t-occ MTG } \\
\text { р MTG }\end{array}$ & $\begin{array}{l}20 \\
20\end{array}$ & - \\
\hline$\Delta \mathrm{ASS}^{\mathrm{ERR}}$ & $f a c$ & 4.04 & .001 & .036 & 4.9 & $\begin{array}{l}-57 \\
-60\end{array}$ & $\begin{array}{l}-47 \\
-20\end{array}$ & $\begin{array}{l}-17 \\
-24\end{array}$ & $\begin{array}{l}\text { ITG } \\
\text { ITG }\end{array}$ & $\begin{array}{c}\text { t-occ ITG } \\
\text { p ITG }\end{array}$ & $\begin{array}{l}20 \\
20\end{array}$ & $x$ \\
\hline $\operatorname{cov} U N R$ & inh & $\begin{array}{l}3.67 \\
0.32 \\
0.23\end{array}$ & .005 & $\begin{array}{l}.006 \\
.032 \\
.040\end{array}$ & $\begin{array}{l}3.2 \\
2.9 \\
2.8\end{array}$ & $\begin{array}{l}-46 \\
-46 \\
-46\end{array}$ & $\begin{array}{l}14 \\
-48 \\
-50\end{array}$ & $\begin{array}{c}-9 \\
9 \\
13\end{array}$ & $\begin{array}{l}\text { insula } \\
\text { MTG } \\
\text { STG }\end{array}$ & $\begin{array}{c}\text { t pole } \\
\text { t-occ MTG } \\
\text { pl polare }\end{array}$ & $\begin{array}{c}? \\
21 \\
-\end{array}$ & - \\
\hline$\triangle \mathrm{CAT}^{\mathrm{LAT}}$ & inh & 11.87 & .010 & .039 & 4.4 & $\begin{array}{l}-37 \\
-58\end{array}$ & $\begin{array}{l}11 \\
19\end{array}$ & $\begin{array}{c}27 \\
7\end{array}$ & $\begin{array}{l}\text { IFG tri } \\
\text { IFG tri }\end{array}$ & $\begin{array}{l}\text { IFG oper } \\
\text { IFG oper }\end{array}$ & $\begin{array}{c}- \\
44 / 45\end{array}$ & $x$ \\
\hline cov MEAN & inh & 4.93 & .005 & .043 & 3.5 & $\begin{array}{l}-58 \\
51\end{array}$ & $\begin{array}{l}19 \\
12\end{array}$ & $\begin{array}{c}5 \\
26\end{array}$ & $\begin{array}{l}\text { IFG tri } \\
\text { IFG oper }\end{array}$ & $\begin{array}{l}\text { IFG oper } \\
\text { IFG oper }\end{array}$ & $\begin{array}{l}- \\
44\end{array}$ & $x$ \\
\hline$\triangle C A T^{E R R}$ & fac & $\begin{array}{l}0.12 \\
0.03 \\
0.01\end{array}$ & .001 & $\begin{array}{l}.017 \\
.029 \\
.038\end{array}$ & $\begin{array}{l}3.84 \\
3.84 \\
3.84\end{array}$ & $\begin{array}{l}-45 \\
-68 \\
-57\end{array}$ & $\begin{array}{l}-8 \\
-25 \\
-56\end{array}$ & $\begin{array}{l}-39 \\
-20 \\
-10\end{array}$ & $\begin{array}{l}\text { ITG } \\
\text { ITG } \\
\text { ITG }\end{array}$ & $\begin{array}{c}\text { a ITG } \\
\text { p MTG } \\
\text { t-occ ITG }\end{array}$ & $\begin{array}{l}20 \\
20 \\
37\end{array}$ & $x$ \\
\hline $\operatorname{cov} U N R$ & $f a c$ & 0.08 & .001 & .028 & 3.75 & -45 & -8 & -39 & ITG & a ITG & 20 & $x$ \\
\hline
\end{tabular}

Table 2: Significant clusters from lesion-behavior analysis. In $2^{\text {nd }}$ column $\uparrow$ indicates that lesions lead to increases in overall errors / latency (ERR $\mathrm{ALL}^{\mathrm{ALA}} \mathrm{LAT}^{\mathrm{MEAN}}$ ); for $\triangle \mathrm{ASS}$ and $\triangle \mathrm{CAT}$ fac indicates that a lesion in the cluster correlates with an increase in facilitation, while inh indicates an increase in inhibition. Statistical threshold at uncorrected voxel-level ( $\boldsymbol{p}$ of base) and after multiple comparison correction at the cluster-level ( $\boldsymbol{p} @$ cluster) are provided. $\mathrm{MNI}$ coordinates of the cluster-peaks (bold) and of local peaks correspond to anatomical structures according to three standard atlases. Last column indicates whether or not lesion size was included as a covariate. STG/ MTG/ ITG - superior/ middle/ inferior temporal gyrus; IFG inferior frontal gyrus; t pole temporal pole; pl polare planum polare; a/p/t-occ anterior/posterior/ temporo-occipital part of the respective gyrus; tri/oper pars triangularis/ opercularis of IFG. 


\subsection{Lesion-analysis}

In participants with focal brain lesions variance of both lesion-site and performance allows for statistical inference about key structures affording the respective task (Bates et al., 2003). Following this rationale we correlated different measures of overall naming performance, and the effects elicited by semantic context with individual lesion patterns. Results are described below and illustrated in Figure 3 and 4; details on size, anatomical site, and statistical robustness of statistically significant lesion-behaviour correlations are provided in Table 2 .

\subsubsection{Lesion patterns correlating with overall performance}

Robust correlations were seen between absolute overall values for ERR and LAT and lesions in the MTG and ITG including the underlying white matter. Figure $\mathbf{3 A}$ shows the clusters for overall errors and mean latency across all responses (ERR ${ }^{\text {ALL }}$ and LAT $\left.{ }^{\text {MEAN }}\right)$. The clusters show substantial overlap, with a somewhat more lateral extension of the cluster for ERR ${ }^{\text {ALL }}$. They comprise large portions of the MTG, ITG reaching to the temporo-parietal junction. Patients with lesions in this part of the language network (details in Table 2) will be slower and less often correct in overall picture naming.

\subsubsection{Lesion patterns correlating with facilitatory / inhibitory effects (A related - unrelated)}

Next, we analysed the two modulatory effects induced by semantic context. Note that ASS is expected to facilitate naming yielding a negative $\triangle \mathrm{ERR}$ and $\triangle \mathrm{LAT}$, whereas for CAT the opposite effect and therefore positive $\Delta \mathrm{ERR}$ and $\Delta \mathrm{LAT}$ are expected. However, lesions can interfere in a complex manner with the $\triangle \mathrm{ERR}$ and $\triangle \mathrm{LAT}$ : A lesion in an area considered critical for, e.g., facilitation should reduce facilitation while it is possible that lesions in another area supporting inhibition may increase facilitation. Hence, analyses for these parameters were performed in both directions. Results are illustrated in Figure $\mathbf{3 B}$. 
For the associative condition lower values of $\triangle \mathrm{ASS}^{\mathrm{ERR}}$ correlated with a cluster in the MTG/ITG. This indicates a lesion in this area increases the facilitatory effect of the associatively related word prime (less errors for related when compared to unrelated words). No correlations were found for the inverse correlation, that is a decrease in facilitation for the associative condition (but see 3.3.3. for results after factoring out overall performance). For the categorical condition $\Delta \mathrm{CAT}^{\mathrm{LAT}}$ most prominently showed an inverse correlation with lesions in the IFG indicating that lesions in this area lead to an increase in naming latency for the categorical when compared to the unrelated condition. Three very small clusters in the ITG/MTG showed a positive correlation with $\triangle \mathrm{CAT}^{\mathrm{ERR}}$, suggesting that lesions in these areas reduce the inhibitory effect of a categorical relation between the word and the picture.

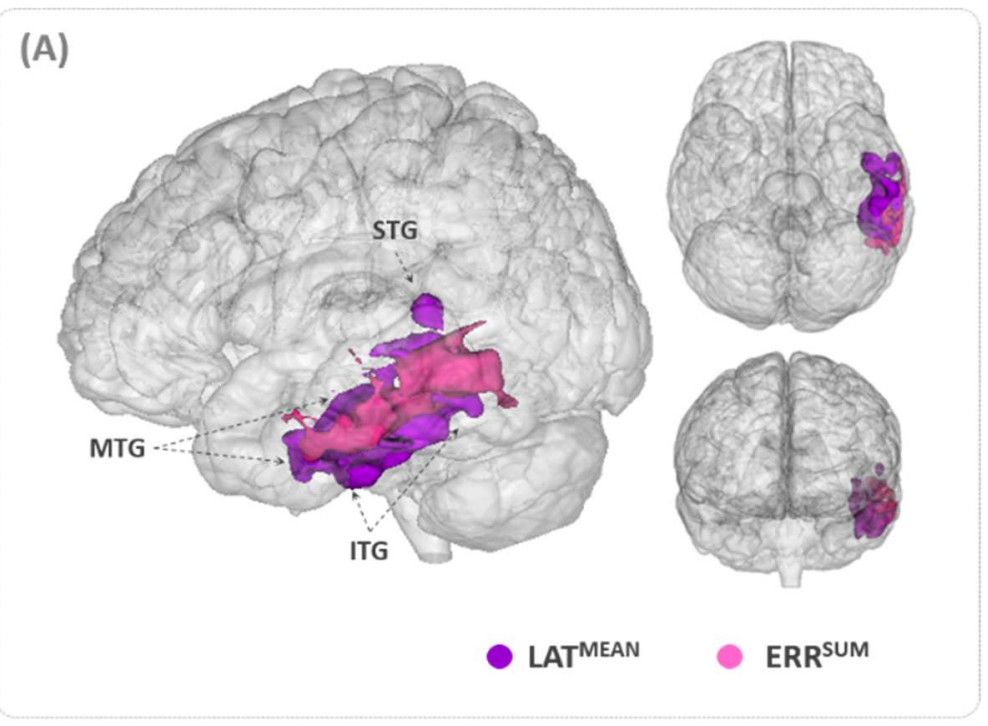

(B)

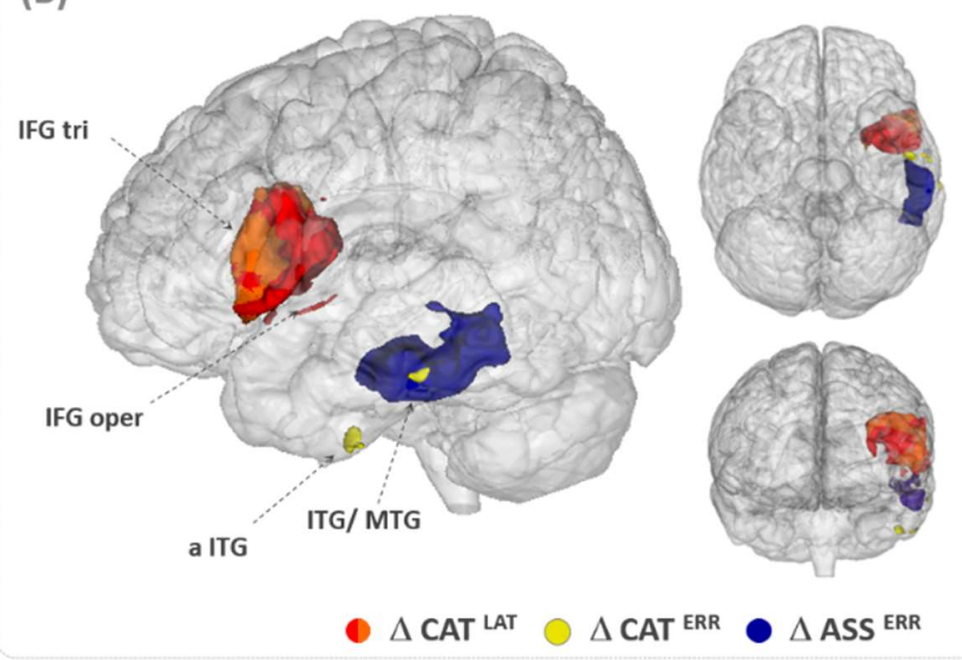

Figure 3: Results of the lesionbehavior analysis (VLSM). (A) Lesions in the illustrated clusters correlate with overall higher error rates $\left(E R R^{A L L}\right.$, pink) and higher latencies (LAT ${ }^{\text {MEAN }}$, purple) in middle and inferior temporal gyrus (MTG, ITG) extending to parts of the superior temporal gyrus (STG) for latency. There is substantial overlap between both clusters. (B) Correlations for the difference between related minus unrelated items results in distinct clusters for either condition: $\triangle$ ASS ${ }^{\mathrm{ERR}}$ decreased with lesions in the inferior-middle temporal cluster (blue) indicating an increase in facilitation (less errors, blue volume). For $\triangle C A T^{L A T}$ lesions in the IFG correlated with an increase in inhibition (longer latencies, redorange volume) while three small clusters (yellow) in the MTG/ITG and anterior ITG (a ITG) correlate with a decrease in inhibition for this condition (see Table 2 and text for details on the clusters and Supplemental Figure SF3 for tomographic representation of the clusters). 


\subsubsection{Factoring out overall performance}

Because overall error rate and latency strongly determine absolute individual performance we additionally performed VLSM analyses in which overall performance was factored out by including ERR ${ }^{\mathrm{ALL}}$ or LAT ${ }^{\mathrm{MEAN}}$ as a covariate. As ERR ${ }^{\mathrm{ALL}}$ or LAT $\mathrm{MEAN}^{\mathrm{M}}$ include the semantically related conditions we additionally performed the same analysis using the mean only across unrelated items. In Table 2 the statistically relevant results are provided as cov MEAN and cov $U N R$ respectively. These analyses confirmed the lesion-effect in the IFG cluster for $\triangle \mathrm{CAT}^{\mathrm{LAT}}$ (orange cluster in Fig. $3 \boldsymbol{B}$ ) and the small temporal cluster for the inverse relation $\triangle \mathrm{CAT}^{\mathrm{ERR}}$. For the associative condition, clusters in the insula, temporal pole and planum polare showed a correlation with an increase in $\triangle \mathrm{ASS}^{\mathrm{ERR}}$. This indicates that for the associative condition posterior temporal lesions increase whereas anterior temporal lesions decrease the expected facilitatory effect (see Table 2 and Figure 4 for a visualization).

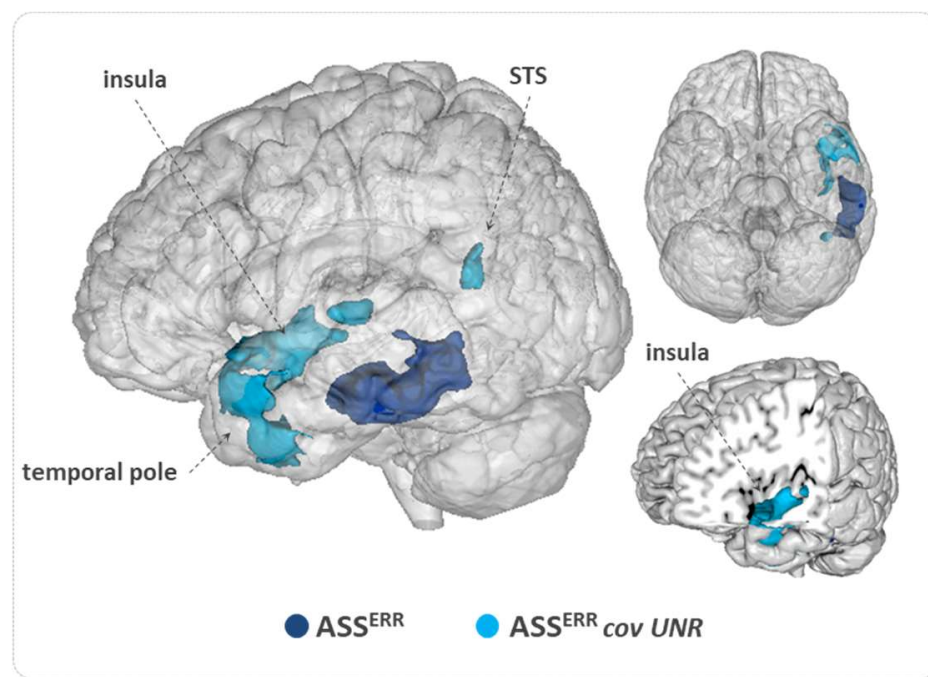

Figure 4: Opposite effects of distinct lesion sites on associative facilitation: Lesions in the posterior temporal cluster (dark blue, identical to Fig. 3B) enhanced the facilitatory effect for the associative related when compared to unrelated item. When factoring out the naming performance of the unrelated condition (covUNR) a non overlapping anterior temporal cluster (light blue) became significant, which reduced the facilitatory effect. For details of the clusters please refer to Table 2.

\subsubsection{Effect of lesion size}

Lesion size was computed as the diameter of a sphere containing the lesion volume (DiaSph). Correlations with this measure was significant only for overall error rate (DiaSph $\leftrightarrow \mathrm{ERR}^{\mathrm{ALL}}: \mathrm{R}^{2}$ $=0.18, p=.015)$. The effect of lesion size correction is controversial, therefore all analyses were performed twice, with and without lesion size as a covariate. The last column in Table 2 
indicates whether or not lesion size was factored out in the respective analysis (DiaSph: ' $\mathrm{x}$ '/ ‘_'). Note that all analyses reported showed at least trends $(p<0.1 @$ the cluster level) when the corresponding other VLSM-model (with or without lesion correction) was run.

\subsubsection{Comparison between subgroups with selective anterior or posterior lesions}

Since previous work on a PWI-paradigm in participants with a left hemispheric lesion used group comparisons instead of the here reported VLSM approach (Piai et al., 2015, Piai and Knight, 2018) we performed an additional analysis on two subgroups of our cohort. To this end we selected participants whose lesions were restricted to either the anterior (BA44/45/46) or posterior (BA 20/21/22) hub. This yielded 8 participants in each group; lesions in the other participants affected both $(n=9)$ or neither region $(n=7)$. Compared to the overall mean, participants with a selective lesion in the anterior hub should show stronger inhibition in the categorical condition while this should not hold for participants with a selective lesion in the posterior hub. Conversely, a selective lesion in the posterior hub should lead to show stronger than average facilitation for the associative condition. To check this prediction we compared ztransformed latencies between the two groups (with $n=8$ in each group), predicting: $\Delta \mathrm{CAT}^{\text {ant }}>\Delta \mathrm{CAT}^{\text {post }}$ and $\Delta \mathrm{ASS}^{\text {ant }}<\Delta \mathrm{ASS}^{\text {post }}$. Results confirmed the prediction for the categorical condition $\left(\Delta \mathrm{CAT}^{\mathrm{LAT}}: \mathrm{t}=2.07 ; \mathrm{df}=14, p=.029 * ; \Delta \mathrm{CAT}^{\mathrm{ERR}}: \mathrm{t}=2.07 ; \mathrm{df}=14, p=.061^{\$}\right)$ but not for the associative condition $\left(\Delta \mathrm{ASS}^{\mathrm{LAT}}: \mathrm{t}=0.71 ; \mathrm{df}=14, p=.756 ; \Delta \mathrm{ASS}^{\mathrm{ERR}}: \mathrm{t}=0.357\right.$; $\mathrm{df}=14, p=.637)$. Lesion distribution of the two subgroups and $\mathrm{z}$-value comparisons are illustrated in figure 5. 


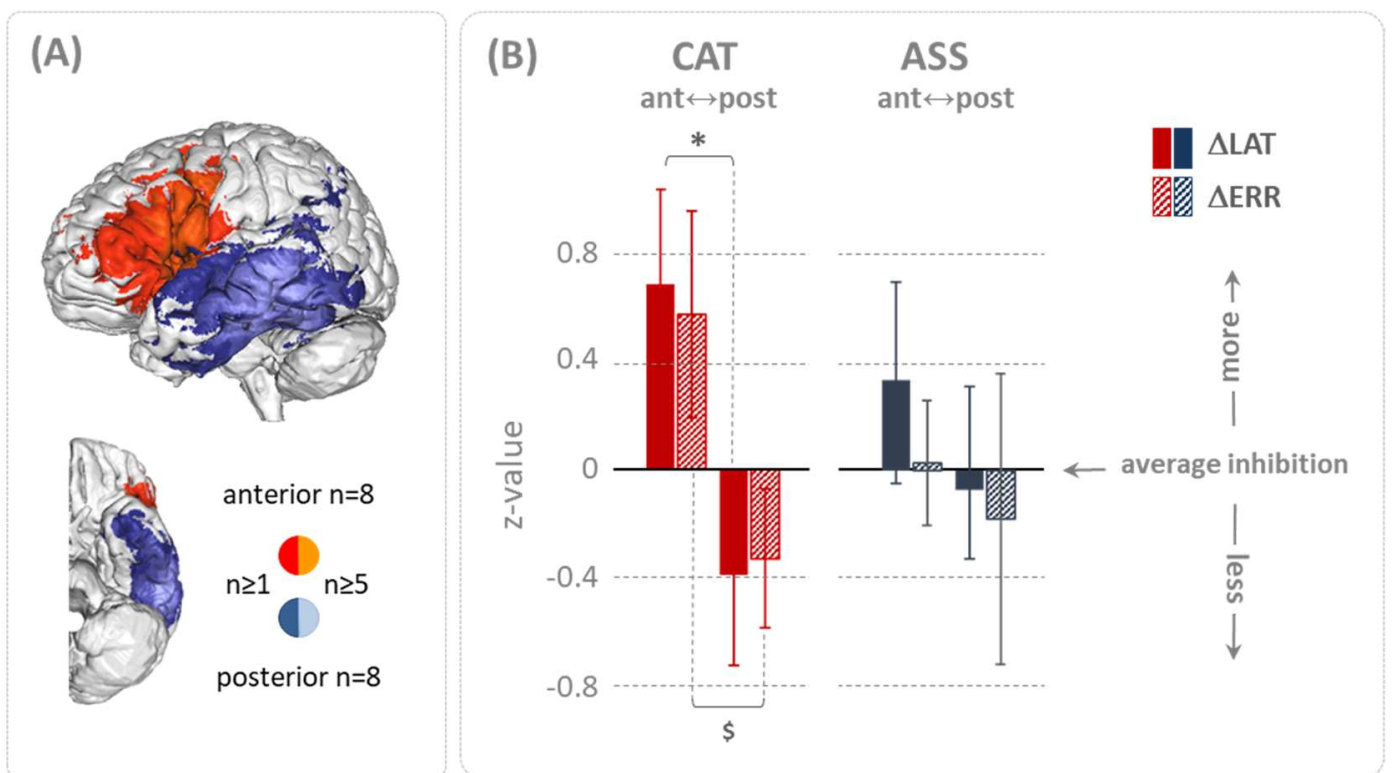

Figure 5: (A) Lesion overlap of participants with lesions selectively affecting anterior $(n=8)$ or posterior $(n=8)$ areas. The lesions did not overlap across groups but show largest within group overlap in the two areas which resulted from our VLSM analysis (figure 3). (B) z-values for the two conditions (ASS/CAT) comparing anterior and posterior subgroups. Positive z-values indicate above average inhibition (i.e. LAT and ERR: related>unrelated). CAT shows the predicted difference between groups the inverse prediction for ASS (larger z-values for posterior group indicating above average facilitation) was not confirmed.

\section{Discussion}

People with aphasia (PWA) sometimes produce the word 'cat' when referring to a dog, albeit being fully aware of the difference between the two animals. Such errors supply clinical evidence for lesions to impair specific aspects of lexico-semantic competence. According to competitive models, such speech production errors are explained by activation of a lexical cohort (e.g. animals) but erroneous choice of the entry. While it is controversial at which level word production encounters competition or lateral inhibition or suffers from refractory downregulation due to repeated presentation, the fact of interference between members of a lexical cohort has been evidenced in numerous studies in neurotypical (e.g. Starreveld and La Heij, 2017, Jescheniak et al., 2014, Rose et al., 2019) and brain-lesioned participants (e.g. Ries et al., 2015, Piai and Knight, 2018, Harvey and Schnur, 2016). Evidence for the opposite effect, that is facilitation of word production by semantically related primes, has been demonstrated in neurotypical participants, with the type of relationship of the distractor (e.g. Henseler et al., 
2014) being the most robust modulator of the effect polarity (also see van Scherpenberg et al., 2020) for a discussion for a PWI paradigm including eyetracking). To capture partially contradictory results, both effects (i.e. interference and facilitation) can be conceived to cooccur, operating differentially at lexical, pre- and post-lexical levels as suggested by sensitivity to timing and the kind of semantic relation. Most parsimoniously a recent model considers the net-effect a summation of semantic context factors including the size of the cohort ('swinginglexical-network model', Abdel Rahman and Melinger, 2009, Abdel Rahman and Melinger, 2019).

Investigating semantic context effects in patients with a lesion in the left hemispheric language network we here show a remarkably clear functional-anatomical double dissociation between net-inhibition and net-facilitation effects: lesions in the anterior hub of the network (IFG, BA 44/45) correlated with an increased interference when a categorically related word preceded the to-be-named picture. Conversely, lesions to the posterior hub (mid-posterior MTG/ITG, BA 20) increased facilitation for associatively related word primes. Notably these effects dissociate behaviourally and are not simply an effect of overall naming performance. The latter correlates with a large area in the STG/ MTG confirming results of previous lesion studies (Baldo et al., 2013, Pillay et al., 2017). The anatomical double-dissociation is relevant for models of word production. Moreover, while response latency are mostly reported in healthy volunteers, the effects most consistently affect overt errors in patients, which allows for perspectives regarding strategies for re-acquisition of lexical competence in PWA.

The findings are in line with a 'division of labour' for lexical retrieval between the two major left hemispheric language hubs: while the posterior hub affords activation of lexical entries including potential interference and facilitation (de Zubicaray et al., 2017, de Zubicaray et al., 2014), the inferior frontal cortex seems essential for selection (Belke and Stielow, 2013, Schnur et al., 2009). The relevance of selection deficits after an acquired lesion to the extended 
language network has been highlighted by theoretical work (Nozari and Hepner, 2019) and has been suggested to result from a maladaptive change in the selection threshold using a driftdiffusion-model in 9 patients with left prefrontal cortex lesions (Anders et al., 2017). Hence, lesions affecting the IFG can be expected to impair selection while lesions in the posterior MTG should impact on lexical activation affecting competition or interference between cohort members. In the following we discuss the functional-anatomic dissociation of both effects and will then briefly turn to the behavioural results and a potential clinical perspective.

\section{Lesions to left inferior frontal gyrus impair selection when lexical entries compete}

We find that the size of the individual interference effect ( $\triangle C A T^{\mathrm{LAT}}$, categorically relatedunrelated) correlates with lesions in the left IFG. This VLSM finding is confirmed by a subgroup analysis, in that participants with a selective lesion in the anterior hub show stronger inhibition in the categorical condition compared to participants with selective lesions in the posterior hub. Previous reports on interference effects after IFG lesion yielded partially similar but inconsistent results. In two patients with left IFG lesion, enhanced naming latencies for categorically related items was interpreted to signal IFG's central role for attentional control when resoling word-meaning interference (Vuong and Martin, 2011). Similarly 6 patients with IFG lesions showed enhanced interference in a blocked cyclic naming paradigm (Ries et al., 2015). Interestingly patients showed no difference to the healthy control group in a continuous naming paradigm. The authors therefore suggest that proactive control of selection bias is mandatory for IFG involvement. Another, elegant combined approach, investigated a blocked cyclic naming paradigm by fMRI in healthy participants and compared findings to lesion data

of 12 patients (Schnur et al., 2009). Left IFG showed activation correlating with the semantic blocking interference. In conjunction with the lesion analysis a critical role of 'Broca's area' for lexical competition resolution is posited. 
While these studies support a role of IFG in semantic interference, other lesion-based studies showed small (Harvey and Schnur, 2015) or no effects (Piai and Knight, 2018). In a review of over 20 neurolinguistic studies investigating semantic interference in the PWI paradigm in healthy adults and patients there was also no robust correlation between the IFG and the occurrence of semantic interference (de Zubicaray and Piai, 2019). To further complicate matters, in a study comparing 6 patients with left ventrolateral prefrontal lesions to healthy controls, patients showed enhanced phonological priming, enhanced sensitivity to any kind of lexical distractors (compared to a no-distractor condition), but showed no semantic interference effect (Piai et al., 2015). The conclusion that PFC is not relevant for interference resolution is surprising, given that healthy controls robustly showed the effect. We suggest that absence of an interference effect after PFC lesion rather points to a modulation of semantic control, interestingly abolishing rather than then augmenting the effect.

To sum up our results provide the as yet most robust evidence for left IFG lesions to enhance categorical interference in a PWI paradigm. Together with studies in healthy volunteers (e.g. Abel et al., 2012, Henseler et al., 2014) we suggest this indicates a central role of the IFG for lexical selection processes, especially in tasks with high competition between simultaneously activated lexical entries. This implies that the impairment in patients with frontal lesions may indeed result from a maladaptive change in the threshold at which the lexical candidate is selected (i.e. 'creterion' in drift-diffusion-model (DDM) terminology; Nozari and Hepner, 2019). Interestingly a recent study following the DDM rationale predicted this difference testing neurotypical and participants with pMTG and IFG lesions on a picture matching task (Todorova et al., 2020). Neurotypical participants increased the decision threshold for the more challenging related condition while drift rate did not change. Participants with lesions in the language network showed a slowed information accumulation (drift) and a lowered decision threshold, highlighting that both lexico-semantic processing and 'conflict resolution' contribute 
to the deficit. However, for the task used in that experiment the expected difference between the MTG-lesion and the IFG-lesion group was not found.

\section{Lesions to left posterior temporal areas increase facilitatory effect of associative primes}

At first glance the second main result of our study is counterintuitive. Increased facilitation of naming when an associative prime precedes the to-be-named picture seems at odds with the notion that lesions should impair, rather than facilitate naming. However, the lesion cluster for augmented associative facilitation (blue cluster in fig. $3 \boldsymbol{B}$ ) partially overlaps with the larger cluster in which lesions lead to more impaired overall naming (pink/purple clusters in fig. $3 \boldsymbol{A}$ ). In other words, patients with overall more impaired naming will profit more strongly from associative primes, when lesioned in the smaller posterior temporal cluster. Indeed when factoring out naming performance on unrelated distractor words, a distinct lesion cluster in the anterior temporal lobe (ATL) and insular regions correlates with lesser facilitation for the associative prime condition (fig. 4, light blue cluster). The findings are consistent with a view that damage to the posterior part of MTG / ITG reduces activation of the lexical target but importantly also its competitors. In that case preserved semantic knowledge on associative relations will become more relevant, boosting the facilitatory effect. Since we did not assess non-verbal semantics, an explanation for the effect of lesions to the ATL is tentative: lesions to anterior temporal cortex may degrade the facilitatory effect of associative primes due to an impairment for supramodal semantic representation, relying on the integrity of the (bilateral) anterior temporal lobe (for an excellent review see Lambon Ralph, 2014).

We are not aware of studies showing changes in associative facilitation after focal lesions. However, partial support for the above interpretation comes from a lesion study in 15 patients with left hemispheric stroke (Harvey and Schnur, 2015). Lesions in posterior MTG enhanced interference effects for a blocked naming paradigm, in which interference is expected comparable to the categorical condition in the present study. "Noisy access to lexical 
representations" is suggested to increase the interference effect. Conversely for a comprehension task (word-picture matching) lesions in anterior portions of the temporal lobe enhanced interference indicating "noisy access to semantic representations". The partially replicated results (Piai and Knight, 2018) highlight that interference may impact at different levels of lexical retrieval (Harvey and Schnur, 2016). Regarding our findings in associative priming we suggest that if lexical and semantic representations rely on different key areas, lesions in posterior and anterior temporal lesions may well modulate associative priming in opposite directions.

(A)
ASSOCIATIVE

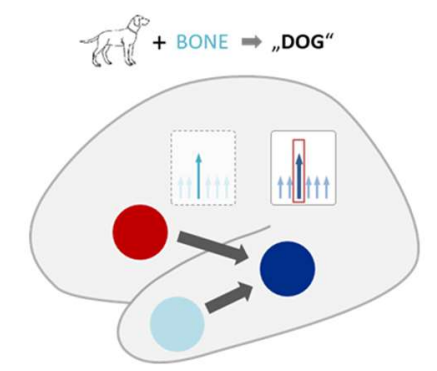

(B)
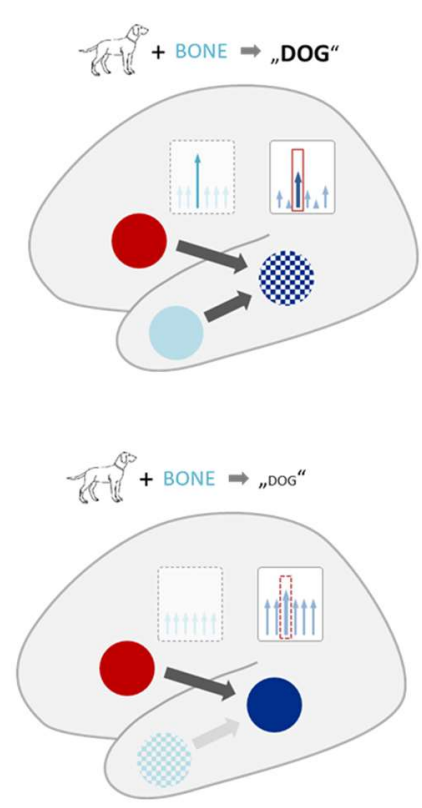

CATEGORICAL

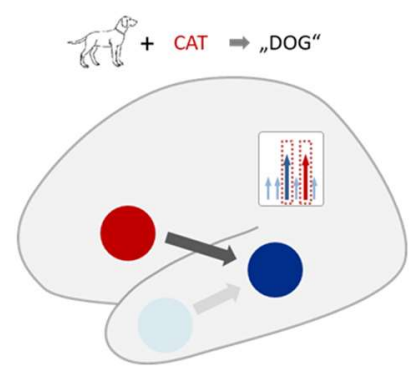

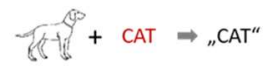

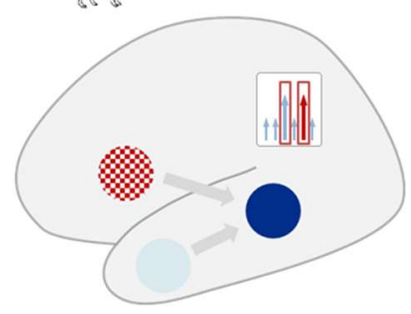

target

associate
Figure 6: Sketch summarizing categorical interference and associative facilitation effects in the present study. (A) In the intact network an associative prime ('BONE'), leads to overall facilitation since semantic facilitation is not counteracted by competition within the lexical cohort (here: pets). When a cohort member is pre-activated ('CAT') this increases interference. (B) Three lesion scenarios; upper left: If posterior temporal cortex (blue) is affected this leads to a noiser access to the target but also to its competitors. In this case associative facilitation is more efficient; upper right: If the IFG (red) is lesioned the selection process is impaired leading to higher error-rates and reaction time; lower left: If the anterior temporal cortex (light blue) is lesioned this reduces the supramodal semantic activation which can be considered central to associative facilitation.

area lesioned

More albeit indirect support for the interpretation of our results comes from two transcranial direct current stimulation (tDCS) studies. In a study using the identical paradigm and material 
as the present study, anodal tDCS over left pMTG elicited a decrease in associative facilitation (Henseler et al., 2014). Since anodal stimulation should enhance excitability in the underlying area, the finding is perfectly complementary to our finding that lesions to posterior temporal cortex increase associative facilitation. Moreover, another study on a blocked cyclic naming paradigm showed that anodal sham-controlled tDCS over left STG increased the categorical interference effect (Pisoni et al., 2012). This supports the view that upregulation of the posterior temporal cortex may augment activation of the target word but likewise activation of its lexical cohort, leading to enhanced competition and interference. Therefore downregulation of the area by a lesion plausibly reduces competition within the cohort boosting the effect of associative priming.

We conclude that our data support a model in which left posterior temporal areas are pivotal to activation of the lexical target but importantly also for co-activation of lexical cohort competitors. While associative (conceptual) semantic representations may rely on anterior temporal regions as a supramodal hub, the IFG is central to selection and conflict-resolution especially in high-demand instances. Comparing patients with semantic dementia (SD) and chronic stroke patients, the causal lesion location for semantic deficits has been differentiated, despite superficially similar difficulties (Jefferies and Lambon Ralph, 2006). In line with our tentative interpretation the authors propose an amodal semantic deficit in SD patients to be housed in bilateral ATL, while in stroke patients lesions either in the IFG or posterior temporoparietal areas yield deficits in semantic access and control.

Figure 6 provides a deliberately simplified sketch of the different scenarios. This may be the basis to detail the dynamic network architecture in future work.

\section{$\underline{\text { Interference and facilitation are relevant for naming abilities of people with aphasia }}$}

At the group-level naming accuracy was reliably modulated in both semantic contexts, while latencies only showed the categorical inhibition but not the associative facilitation. This 
highlights that the effects sometimes demonstrated as subtle latency differences in neurotypical participants, are behaviourally relevant in people with aphasia (PWA). Indeed errors due to categorical inhibition match clinically observable patterns for spontaneous speech of PWA, in that semantic paraphasias largely replace the target by a categorical neighbour (e.g. cat $\rightarrow$ dog) (Schwartz, 2014). Conversely, the use of facilitatory effects of associative (and supra-ordinate) relations is a key feature of the 'semantic feature analysis therapy' (Efstratiadou et al., 2018). We therefore believe that the highly experimental manipulation performed in the present study is potentially relevant for clinical perspectives.

Explanations for different sensitivities of the parameters to associative priming effects remain speculative, since previous studies in PWA mostly focus either on errors (Harvey and Schnur, 2015, Schwartz, 2014) or selectively report latencies (e.g. Schnur et al., 2009). A tentative explanation rests on a modelling approach comprising 'evidence accumulation' and 'threshold adjustment' as relevant but potentially selectively impaired parameters (Anders et al., 2017, Nozari and Hepner, 2019). In that vein, the 'accumulation of evidence' (i.e. activation of lexical candidates and cohort) is a time sensitive process. Only when this process is successful the selection challenges come into play resulting in failure (paraphasia/no response) or success. Therefore operations intrinsic to the lexicon (activation and competition) will impact on both error rate and latency, while selection depending on threshold adjustment may more prominently affect the correct/ incorrect choice of competing candidates.

Acknowledgments: The research was supported by the institutions listed under affiliations. No external funding was provided.

Competing interests: All authors declare that there is no conflict of interest.

Author contributions: AM, JJ, HO, FR and DP designed the material and the experiment. DP performed the study. DP, AM and HO analyzed the data. DP and HO wrote the paper, assisted by all authors. 


\section{References}

ABDEL RAHMAN, R. \& MELINGER, A. 2009. Semantic context effects in language production: A swinging lexical network proposal and a review. Language and Cognitive Processes, 24.

ABDEL RAHMAN, R. \& MELINGER, A. 2019. Semantic processing during language production: an update of the swinging lexical network. Language, Cognition and Neuroscience.

ABEL, S., DRESSEL, K., BITZER, R., KUMMERER, D., MADER, I., WEILLER, C. \& HUBER, W. 2009. The separation of processing stages in a lexical interference fMRI-paradigm. Neuroimage, $44,1113-$ 24.

ABEL, S., DRESSEL, K., WEILLER, C. \& HUBER, W. 2012. Enhancement and suppression in a lexical interference fMRI-paradigm. Brain Behav, 2, 109-27.

ANDERS, R., RIES, S., VAN MAANEN, L. \& ALARIO, F. X. 2017. Lesions to the left lateral prefrontal cortex impair decision threshold adjustment for lexical selection. Cogn Neuropsychol, 34, 1-20.

ASHBURNER, J. \& FRISTON, K. J. 2005. Unified segmentation. Neuroimage, 26, 839-851.

BADRE, D., POLDRACK, R. A., PARE-BLAGOEV, E. J., INSLER, R. Z. \& WAGNER, A. D. 2005. Dissociable controlled retrieval and generalized selection mechanisms in ventrolateral prefrontal cortex. Neuron, 47, 907-18.

BALDO, J. V., AREVALO, A., PATTERSON, J. P. \& DRONKERS, N. F. 2013. Grey and white matter correlates of picture naming: evidence from a voxel-based lesion analysis of the Boston Naming Test. Cortex, 49, 658-67.

BATES, E., WILSON, S. M., SAYGIN, A. P., DICK, F., SERENO, M. I., KNIGHT, R. T. \& DRONKERS, N. F. 2003. Voxel-based lesion-symptom mapping. Nat Neurosci, 6, 448-50.

BELKE, E. \& STIELOW, A. 2013. Cumulative and non-cumulative semantic interference in object naming: evidence from blocked and continuous manipulations of semantic context. $Q J$ Exp Psychol (Hove), 66, 2135-60.

BINDER, J. R., DESAI, R. H., GRAVES, W. W. \& CONANT, L. L. 2009. Where is the semantic system? A critical review and meta-analysis of 120 functional neuroimaging studies. Cereb Cortex, 19, 2767-96.

BLOEM, I. \& LA HEIJ, W. 2003. Semantic facilitation and semantic interference in word translation: Implications for models of lexical access in language production. Journal of Memory and Language, 48, 468-488.

BLOEM, I., VAN DEN BOOGAARD, S. \& LA HEIJ, W. 2004. Semantic facilitation and semantic interference in language production: Further evidence for the conceptual selection model of lexical access. Journal of Memory and Language, 307-323.

BORTFELD, H., LEON, S. D., BLOOM, J. E., SCHOBER, M. F. \& BRENNAN, S. E. 2001. Disfluency rates in conversation: effects of age, relationship, topic, role, and gender. Lang Speech, 44, 123-47.

BRETT, M., LEFF, A. P., RORDEN, C. \& ASHBURNER, J. 2001. Spatial normalization of brain images with focal lesions using cost function masking. Neuroimage, 14, 486-500.

CAMPANELLA, F. \& SHALLICE, T. 2011. Refractoriness and the healthy brain: a behavioural study on semantic access. Cognition, 118, 417-31.

CONROY, P., SOTIROPOULOU DROSOPOULOU, C., HUMPHREYS, G. F., HALAI, A. D. \& LAMBON RALPH, M. A. 2018. Time for a quick word? The striking benefits of training speed and accuracy of word retrieval in post-stroke aphasia. Brain, 141, 1815-1827.

DAMIAN, M. F. \& BOWERS, J. S. 2003. Locus of semantic interference in picture-word interference tasks. Psychon Bull Rev, 10, 111-7.

DAMIAN, M. F., VIGLIOCCO, G. \& LEVELT, W. J. 2001. Effects of semantic context in the naming of pictures and words. Cognition, 81, B77-86.

DE ZUBICARAY, G., FRASER, D., RAMAJOO, K. \& MCMAHON, K. 2017. Interference from related actions in spoken word production: Behavioural and fMRI evidence. Neuropsychologia, 96, 78-88.

DE ZUBICARAY, G., JOHNSON, K., HOWARD, D. \& MCMAHON, K. 2014. A perfusion fMRI investigation of thematic and categorical context effects in the spoken production of object names. Cortex, 54, 135-49. 
DE ZUBICARAY, G. \& PIAI, V. 2019. Investigating the spatial and temporal components of speech production., Oxford, Oxford University Press.

DE ZUBICARAY, G. I., MIOZZO, M., JOHNSON, K., SCHILLER, N. O. \& MCMAHON, K. L. 2012. Independent distractor frequency and age-of-acquisition effects in picture-word interference: fMRI evidence for post-lexical and lexical accounts according to distractor type. J Cogn Neurosci, 24, 482-95.

DE ZUBICARAY, G. I., WILSON, S. J., MCMAHON, K. L. \& MUTHIAH, S. 2001. The semantic interference effect in the picture-word paradigm: an event-related fMRI study employing overt responses. Hum Brain Mapp, 14, 218-27.

DHOOGE, E. \& HARTSUIKER, R. J. 2011. The distractor frequency effect in a delayed picture-word interference task: further evidence for a late locus of distractor exclusion. Psychon Bull Rev, $18,116-22$.

EFSTRATIADOU, E. A., PAPATHANASIOU, I., HOLLAND, R., ARCHONTI, A. \& HILARI, K. 2018. A Systematic Review of Semantic Feature Analysis Therapy Studies for Aphasia. J Speech Lang Hear Res, 61, 1261-1278.

FINKBEINER, M. \& CARAMAZZA, A. 2006. Now you see it, now you don't: on turning semantic interference into facilitation in a Stroop-like task. Cortex, 42, 790-6.

GLASER, W. R. \& DUNGELHOFF, F. J. 1984. The time course of picture-word interference. J Exp Psychol Hum Percept Perform, 10, 640-54.

HARLEY, T. A. 1993. Phonological Activation of Semantic Competitors during Lexical Access in Speech Production. Language and Cognitive Processes, 8, 291-309.

HARVEY, D. Y. \& SCHNUR, T. T. 2015. Distinct loci of lexical and semantic access deficits in aphasia: Evidence from voxel-based lesion-symptom mapping and diffusion tensor imaging. Cortex, 67, 37-58.

HARVEY, D. Y. \& SCHNUR, T. T. 2016. Different Loci of Semantic Interference in Picture Naming vs. Word-Picture Matching Tasks. Front Psychol, 7, 710.

HENSELER, I., MADEBACH, A., KOTZ, S. A. \& JESCHENIAK, J. D. 2014. Modulating brain mechanisms resolving lexico-semantic Interference during word production: A transcranial direct current stimulation study. J Cogn Neurosci, 26, 1403-17.

HUBER, W., POECK, K. \& WILLMES, K. 1984. The Aachen Aphasia Test. Adv Neurol, 42, 291-303.

JEFFERIES, E. \& LAMBON RALPH, M. A. 2006. Semantic impairment in stroke aphasia versus semantic dementia: a case-series comparison. Brain, 129, 2132-47.

JESCHENIAK, J. D., MATUSHANSKAYA, A., MADEBACH, A. \& MULLER, M. M. 2014. Semantic interference from distractor pictures in single-picture naming: evidence for competitive lexical selection. Psychon Bull Rev, 21, 1294-300.

KOHN, S. E. \& GOODGLASS, H. 1985. Picture-naming in aphasia. Brain Lang, 24, 266-83.

KROLL, J. F. \& STEWART, E. 1994. Category interferences in translation and picture naming: evidence for asymmetric connection between bilingual memory representations. Journal of Memory and Language, 33, 149-174.

LA HEIJ, W. 1988. Components of Stroop-like interference in picture naming. Mem Cognit, 16, 400-10.

LA HEIJ, W., DIRKX, J. \& KRAMER, P. 1990. Categorical interference and associative priming in picture naming. British Journal of Psychology, 81, 511-525.

LAMBON RALPH, M. A. 2014. Neurocognitive insights on conceptual knowledge and its breakdown. Philos Trans R Soc Lond B Biol Sci, 369, 20120392.

LEVELT, W. J., ROELOFS, A. \& MEYER, A. S. 1999. A theory of lexical access in speech production. Behav Brain Sci, 22, 1-38; discussion 38-75.

MAESS, B., FRIEDERICl, A. D., DAMIAN, M., MEYER, A. S. \& LEVELT, W. J. 2002. Semantic category interference in overt picture naming: sharpening current density localization by PCA. J Cogn Neurosci, 14, 455-62.

MAHON, B. Z., COSTA, A., PETERSON, R., VARGAS, K. A. \& CARAMAZZA, A. 2007. Lexical selection is not by competition: a reinterpretation of semantic interference and facilitation effects in the picture-word interference paradigm. J Exp Psychol Learn Mem Cogn, 33, 503-35. 
MEINZER, M., FLAISCH, T., WILSER, L., EULITZ, C., ROCKSTROH, B., CONWAY, T., GONZALEZ-ROTHI, L. \& CROSSON, B. 2009. Neural signatures of semantic and phonemic fluency in young and old adults. J Cogn Neurosci, 21, 2007-18.

MELINGER, A. \& WEBER, A. 2006. Database of Noun Associations for German. . http://www.coli.unisaarland.de/projects/nag/.

MUELLER, K. D., KOSCIK, R. L., HERMANN, B. P., JOHNSON, S. C. \& TURKSTRA, L. S. 2017. Declines in Connected Language Are Associated with Very Early Mild Cognitive Impairment: Results from the Wisconsin Registry for Alzheimer's Prevention. Front Aging Neurosci, 9, 437.

NOZARI, N. 2021. Neural basis of word production. In: GLEITMANN, L., TRUESWELL, J. \& PAPAFRAGOU, A. (eds.) Oxford Handbook of the Mental Lexicon. Oxford, UK: Oxford University Press.

NOZARI, N. \& HEPNER, C. R. 2019. To select or to wait? The importance of criterion setting in debates of competitive lexical selection. Cogn Neuropsychol, 36, 193-207.

OPPENHEIM, G. M., DELL, G. S. \& SCHWARTZ, M. F. 2010. The dark side of incremental learning: a model of cumulative semantic interference during lexical access in speech production. Cognition, 114, 227-52.

PIAI, V. \& KNIGHT, R. T. 2018. Lexical selection with competing distractors: Evidence from left temporal lobe lesions. Psychon Bull Rev, 25, 710-717.

PIAI, V., RIES, S. K. \& SWICK, D. 2015. Lesions to Lateral Prefrontal Cortex Impair Lexical Interference Control in Word Production. Front Hum Neurosci, 9, 721.

PILLAY, S. B., BINDER, J. R., HUMPHRIES, C., GROSS, W. L. \& BOOK, D. S. 2017. Lesion localization of speech comprehension deficits in chronic aphasia. Neurology, 88, 970-975.

PISONI, A., PAPAGNO, C. \& CATTANEO, Z. 2012. Neural correlates of the semantic interference effect: new evidence from transcranial direct current stimulation. Neuroscience, 223, 56-67.

PROTOPAS, A. 2007. Check Vocal: A program to facilitate checking the accuracy and response time of vocal responses from DMDX. Behavior Research Methods, 39, 859-862.

RIES, S. K., KARZMARK, C. R., NAVARRETE, E., KNIGHT, R. T. \& DRONKERS, N. F. 2015. Specifying the role of the left prefrontal cortex in word selection. Brain Lang, 149, 135-47.

RIES, S. K., PIAI, V., PERRY, D., GRIFFIN, S., JORDAN, K., HENRY, R., KNIGHT, R. T. \& BERGER, M. S. 2019. Roles of ventral versus dorsal pathways in language production: An awake language mapping study. Brain Lang, 191, 17-27.

ROELOFS, A. 1992. A spreading-activation theory of lemma retrieval in speaking. Cognition, 42, 10742.

ROELOFS, A., PIAI, V. \& SCHRIEFERS, H. 2011. Selective attention and distractor frequency in naming performance: comment on Dhooge and Hartsuiker (2010). J Exp Psychol Learn Mem Cogn, 37, 1032-8.

RORDEN, C. \& BRETT, M. 2000. Stereotaxic display of brain lesions. Behavioural Neurology, 12, 191200.

RORDEN, C., KARNATH, H. O. \& BONILHA, L. 2007. Improving lesion-symptom mapping. Journal of Cognitive Neuroscience, 19, 1081-1088.

ROSE, S. B., ARISTEI, S., MELINGER, A. \& ABDEL RAHMAN, R. 2019. The closer they are, the more they interfere: Semantic similarity of word distractors increases competition in language production. J Exp Psychol Learn Mem Cogn, 45, 753-763.

SCHNUR, T. T., SCHWARTZ, M. F., KIMBERG, D. Y., HIRSHORN, E., COSLETT, H. B. \& THOMPSON-SCHILL, S. L. 2009. Localizing interference during naming: convergent neuroimaging and neuropsychological evidence for the function of Broca's area. Proc Natl Acad Sci U S A, 106, 322-7.

SCHWARTZ, M. F. 2014. Theoretical analysis of word production deficits in adult aphasia. Philos Trans $R$ Soc Lond B Biol Sci, 369, 20120390.

SCHWARTZ, M. F., KIMBERG, D. Y., WALKER, G. M., FASEYITAN, O., BRECHER, A., DELL, G. S. \& COSLETT, H. B. 2009. Anterior temporal involvement in semantic word retrieval: voxel-based lesionsymptom mapping evidence from aphasia. Brain, 132, 3411-27. 
STARREVELD, P. A. \& LA HEIJ, W. 2017. Picture-word interference is a Stroop effect: A theoretical analysis and new empirical findings. Psychon Bull Rev, 24, 721-733.

TODOROVA, L., NEVILLE, D. A. \& PIAI, V. 2020. Lexical-semantic and executive deficits revealed by computational modelling: A drift diffusion model perspective. Neuropsychologia, 146, 107560.

VAN SCHERPENBERG, C., ABDEL RAHMAN, R. \& OBRIG, H. 2020. A novel multi-word paradigm for investigating semantic context effects in language production. PLoS One, 15, e0230439.

VUONG, L. C. \& MARTIN, R. C. 2011. LIFG-based attentional control and the resolution of lexical ambiguities in sentence context. Brain Lang, 116, 22-32. 


\section{Figure and Table legends}

Figure 1: (A) Picture-word paradigm. A fixation cross was followed by the distractor word in the associative condition (ASS; SOA of 300 ms , 'Knochen' engl.: bone) and the categorical condition (CAT; SOA of 100 ms, 'Kirsche' engl.: cherry). The distractor word remained on the screen during target presentation. After the voicekeey was triggered the pictuire remained on the screen fpor another $3 \mathrm{~s}$. Time-out for the voice key trigger was $10 \mathrm{~s}$. display disappeared $3000 \mathrm{~ms}$ after the voice key was triggered. The time window to initiate a response was maximally $10 \mathrm{sec}$. (B) Lesion overlay map of the 32 patients. Coloured areas are lesioned in at least one patient. Lesion-behaviour analyses were performed in areas in which at least 3 lesions overlapped. A more detailed representation of the lesion coverage is supplied in Supplementary Figure 1.

Figure 2: (A) Comparison between categorically and associatively related conditions (CAT, blue and ASS, red bars) and their resepective unrelated controls (grey bars). Categorically related words lead to longer naming latencies (LAT, left) and more errors (ERR, right). Associatively related words facilitated naming correctness (fewer errors) but did not decrease naming latency. Note that unrelated conditions (grey bars) involve different items, thus a direct comparison is not possible. ${ }^{*} p<.05,{ }^{* *} p<.01$, according to paired two-sided tstatistics. (B) Correlations between related ( $x$-axis) and unrelated conditions ( $y$-axis) (CAT, blue and ASS, red). In both outcome parameters (errors in whole numbers, ERR; latency in S, LAT) a strong correlation was seen indicating that the overall level of naming impairment is the major factor causing variance across the cohort. (C) Correlations between naming performance for categorically (CAT, $y$-axis) and associatively (ASS, $x$-axis) related items. While absolute values of ERR and LAT correlate strongly (left graphs, in absolute numbers/ seconds) indicating the major influence of overall naming impairment, the difference between related and the respective unrelated conditions shows no or non-significant correlations (right graphs). This indicates that the size of the facilitatory/ inhibitory effect of the two conditions dissociates in patients (see Supplementary Figure SF2 for another visualisation of this dissociation between effects).

Figure 3: Results of the lesion-behavior analysis (VLSM). (A) Lesions in the illustrated clusters correlate with overall higher error rates (ERR ${ }^{A L L}$, pink) and higher latencies (LAT ${ }^{\text {MEAN }}$, purple) in middle and inferior temporal gyrus (MTG, ITG) extending to parts of the superior temporal gyrus (STG) for latency. There is substantial overlap between both clusters. (B) Correlations for the difference between related minus unrelated items results in distinct clusters for either condition: $\triangle A S S S^{E R R}$ decreased with lesions in the inferior-middle temporal cluster (blue) indicating an increase in facilitation (less errors, blue volume). For $\triangle C A T^{\mathrm{LAT}}$ lesions in the IFG correlated with an increase in inhibition (longer latencies, red-orange volume) while three 
small clusters (yellow) in the MTG/ITG and anterior ITG (a ITG) correlate with a decrease in inhibition for this condition (see Table 2 and text for details on the clusters and Supplemental Figure SF3 for tomographic representation of the clusters).

Figure 4: Opposite effects of distinct lesion sites on associative facilitation: Lesions in the posterior temporal cluster (dark blue, identical to Fig. 3B) enhanced the facilitatory effect for the associative related when compared to unrelated item. When factoring out the naming performance of the unrelated condition (covUNR) a non overlapping anterior temporal cluster (light blue) became significant, which reduced the facilitatory effect. For details of the clusters please refer to Table 2.

Figure 5: (A) Lesion overlap of participants with lesions selectively affecting anterior $(n=8)$ or posterior $(n=8)$ areas. The lesions did not overlap across groups but show largest within group overlap in the two areas which resulted from our VLSM analysis (figure 3). (B) z-values for the two conditions (ASS/CAT) comparing anterior and posterior subgroups. Positive z-values indicate above average inhibition (i.e. LAT and ERR: related>unrelated). CAT shows the predicted difference between groups the inverse prediction for ASS (larger z-values for posterior group indicating above average facilitation) was not confirmed.

Figure 6: Sketch summarizing categorical interference and associative facilitation effects in the present study. (A) In the intact network an associative prime ('BONE'), leads to overall facilitation since semantic facilitation is not counteracted by competition within the lexical cohort (here: pets). When a cohort member is pre-activated ('CAT') this increases interference. (B) Three lesion scenarios; upper left: If posterior temporal cortex (blue) is affected this leads to a noiser access to the target but also to its competitors. In this case associative facilitation is more efficient; upper right: If the IFG (red) is lesioned the selection process is impaired leading to higher error-rates and reaction time; lower left: If the anterior temporal cortex (light blue) is lesioned this reduces the supramodal semantic activation which can be considered central to associative facilitation.

Table 1: Mean naming latencies (LAT in $\mathrm{ms}$ ) and mean number of errors (ERR in whole numbers) and corresponding standard deviations (SD) and ranges. ASS: associatively related condition; CAT: categorically related condition; rel / unrel: related / unrelated prime words; $\Delta^{\text {rel-unrel: }}$ difference related-unrelated conditions.

Table 2: Significant clusters from lesion-behavior analysis. In $2^{\text {nd }}$ column $\uparrow$ indicates that lesions lead to increases in overall errors / latency (ERR ${ }^{\mathrm{ALL}} / \mathrm{LAT}^{\mathrm{MEAN}}$ ); for $\triangle \mathrm{ASS}$ and $\triangle \mathrm{CAT}$ fac indicates that a lesion in the cluster correlates with an increase in facilitation, while inh indicates an increase in inhibition. Statistical threshold at uncorrected voxel-level ( $\boldsymbol{p}$ of base) and after multiple comparison correction at the cluster-level ( $\boldsymbol{p} @$ cluster) are provided. MNI 
coordinates of the cluster-peaks (bold) and of local peaks correspond to anatomical structures according to three standard atlases. Last column indicates whether or not lesion size was included as a covariate. STG/ MTG/ ITG - superior/ middle/ inferior temporal gyrus; IFG inferior frontal gyrus; $\mathbf{t}$ pole temporal pole; pl polare planum polare; a/p/t-occ anterior/posterior/ temporo-occipital part of the respective gyrus; tri/oper pars triangularis/ opercularis of IFG. 


\section{Supplemental Material}

\section{Supplemantal Figure SF1}

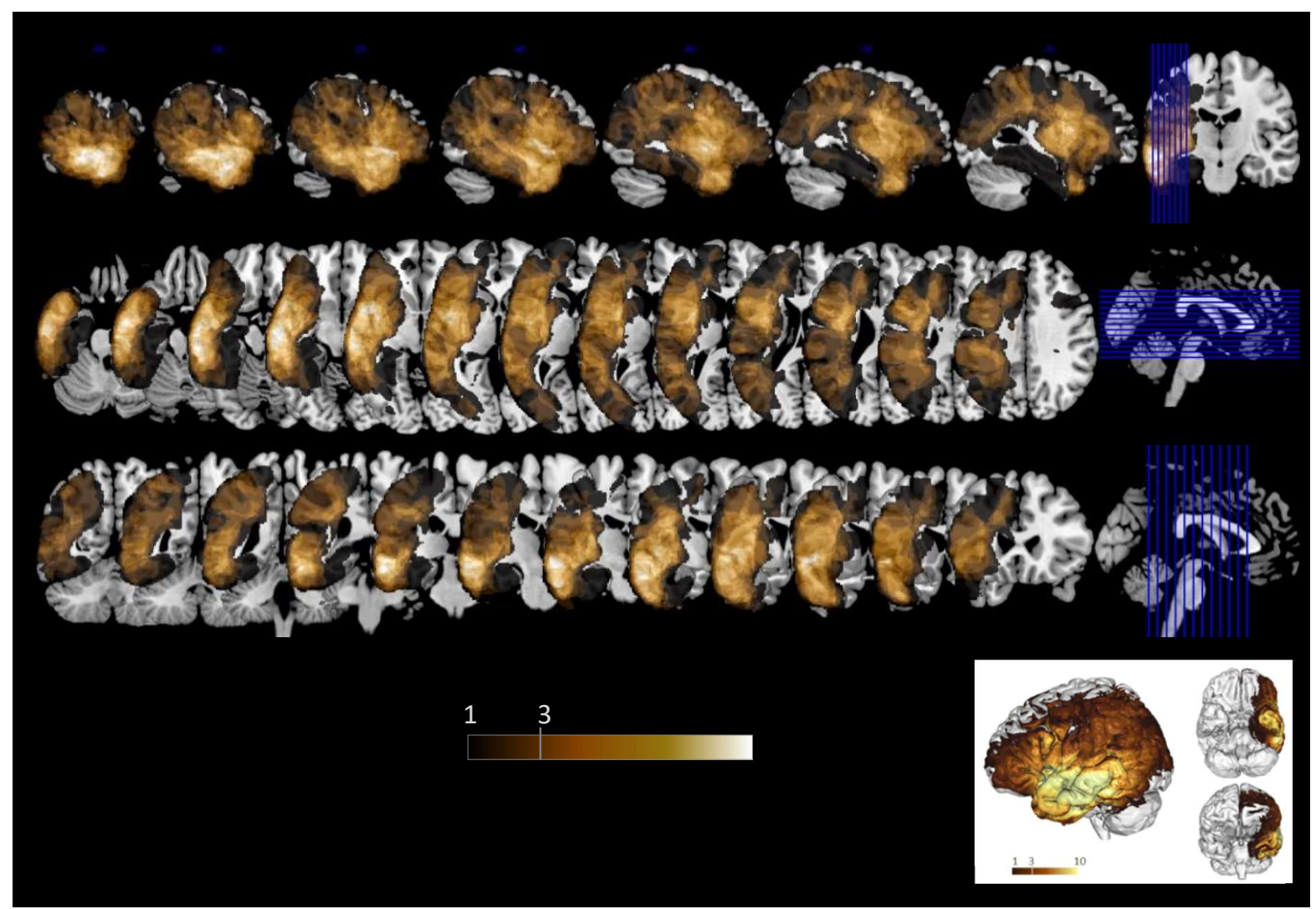

Supplemental Figure SF1: Tomographic representation of lesion coverage and maximal overlap. Inset refers to Figure 1B in the main text. 


\section{Supplemantal Figure SF2}

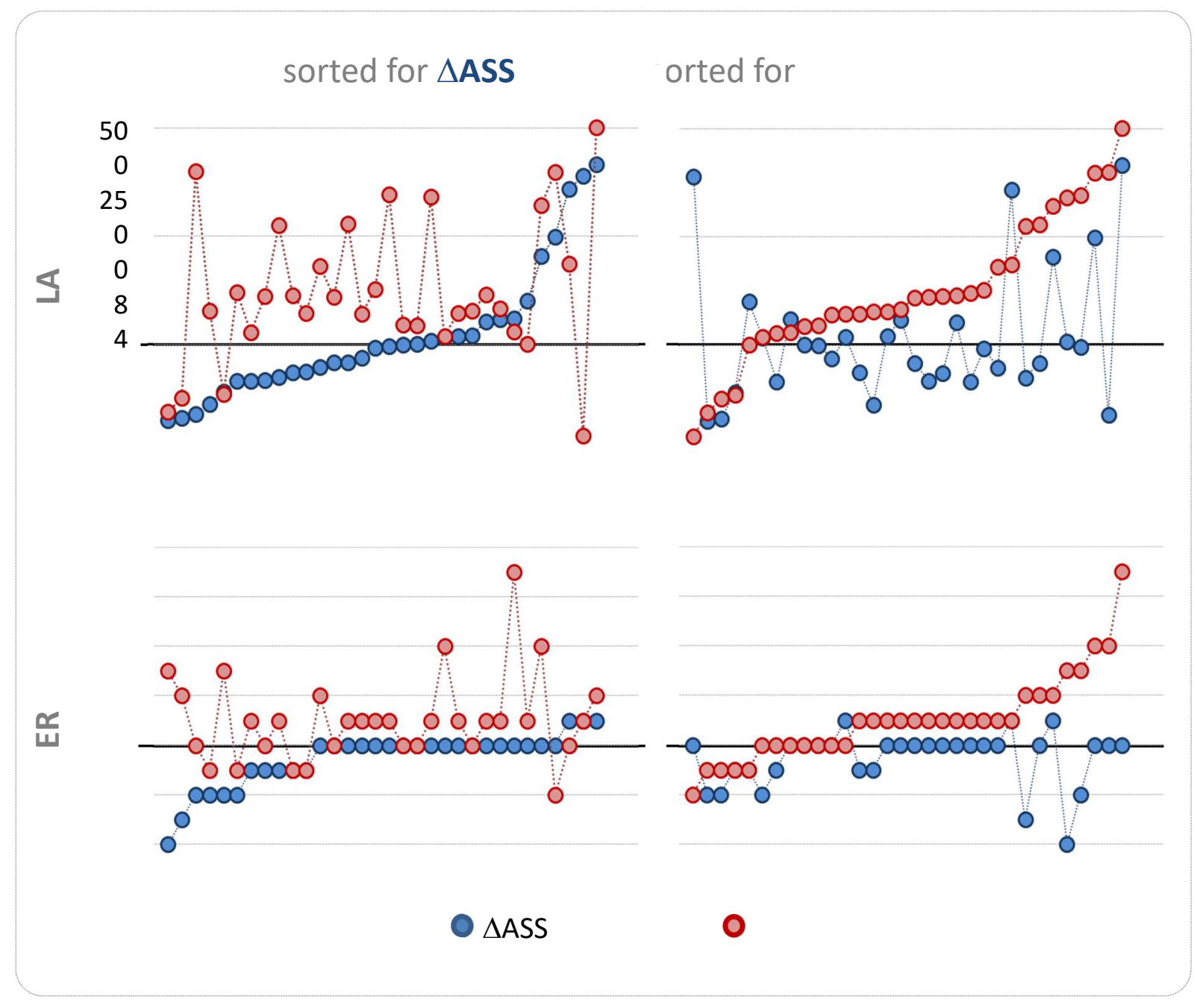

Supplemental Figure SF2: Graphs illustrate that the influence of semantic for the assciative effect ( $\triangle \mathrm{ASS}$ ) and categorical effect $(\triangle \mathrm{CAT})$, both representing the differnece between relatedunrelated items. The effect dissociate across participants. The upper graphs shows latencies (LAT). Participants are ordered according to ascendig size of $\triangle$ ASS (left) or $\Delta C A T$ (right). The illustraions show that the majority of the participants show the expected facilitation for ASS and interfernece for CAT. However, these two effects dissociate across participants. Lower graphs show the same for error rates (ERR) 


\section{Supplemantal Figure SF3}
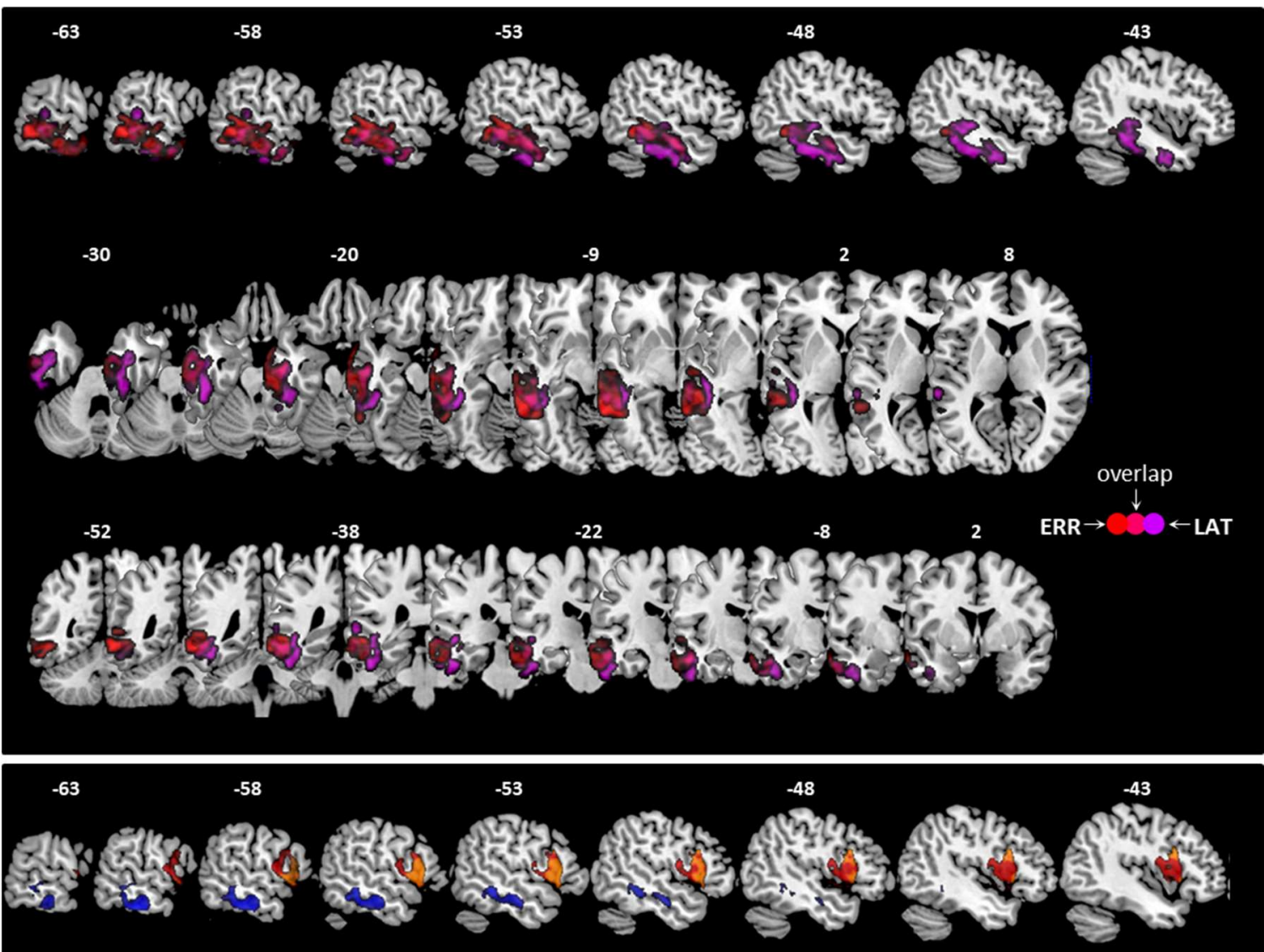

$-35$ $-14$

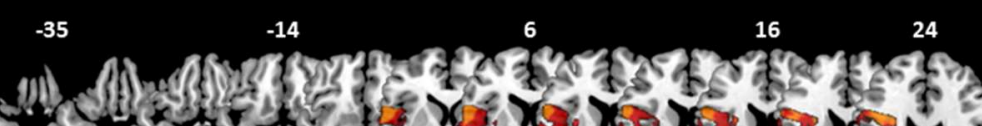

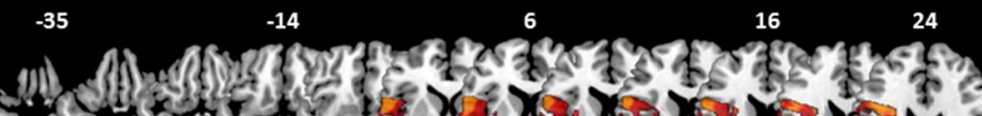

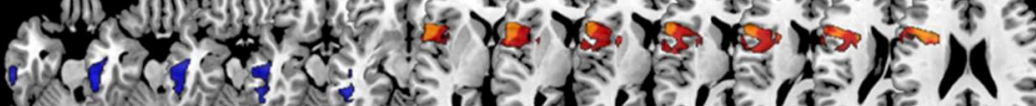
(2.

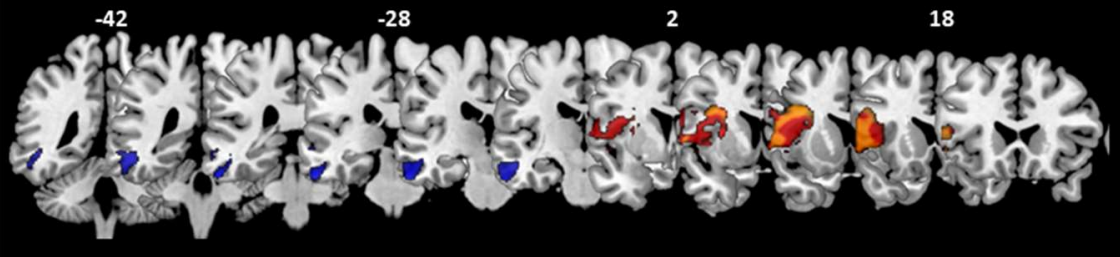

Supplemental Figure SF3: The figure provides a tomographic representation of the clusters illustrated in figure 3 of the manuscript. ERR: error rate; LAT: latency; $\triangle A S S^{E R R}$ : difference related-unrelated for the associative condition; $\triangle C A T^{\mathrm{LAT}}$ : difference related-unrelated for the categorical condition. 


\section{Supplemental Table ST1:}

\begin{tabular}{|c|c|c|c|c|c|c|c|}
\hline & DiaSph & age & m.p.o. & aetiology & site & syndr. & sex \\
\hline 1 & 0.9 & 57 & 26 & MCA inf & int caps & no & $\mathrm{m}$ \\
\hline 2 & 1.1 & 60 & 70 & MCA inf & lentif & no & $\mathrm{f}$ \\
\hline 3 & 1.5 & 60 & 51 & MCA inf & ant MCA & anomic & $\mathrm{f}$ \\
\hline 4 & 1.8 & 63 & 5 & $\mathrm{ICH}$ & basal gang & residual & $\mathrm{f}$ \\
\hline 5 & 2.0 & 67 & 12 & MCA inf & post MCA & residual & $\mathrm{m}$ \\
\hline 6 & 2.4 & 54 & 3 & $\mathrm{ICH} /$ inf & multiple & residual & $\mathrm{f}$ \\
\hline 7 & 2.5 & 58 & 38 & mening & front & no & $\mathrm{f}$ \\
\hline 8 & 2.6 & 44 & 14 & MCA inf & post MCA & unclassif & $\mathrm{m}$ \\
\hline 9 & 2.9 & 52 & 16 & MCA inf & basal gang & residual & $f$ \\
\hline 10 & 2.9 & 38 & 25 & TBI & temp/par & residual & $f$ \\
\hline 11 & 2.9 & 53 & 27 & MCA inf/ TBI & ant MCA /temp & residual & $\mathrm{m}$ \\
\hline 12 & 3.1 & 46 & 13 & MCA inf & multiple left & anomic & $\mathrm{m}$ \\
\hline 13 & 3.1 & 45 & 27 & $\mathrm{ICH}$ & basal gang & residual & $\mathrm{m}$ \\
\hline 14 & 3.1 & 55 & 57 & MCA inf & ant MCA & anomic & $f$ \\
\hline 15 & 3.3 & 76 & 177 & MCA inf & ant MCA & residual & $\mathrm{m}$ \\
\hline 16 & 3.8 & 48 & 12 & $S A H \rightarrow M C A / A C A$ inf & ant/post MCA & residual & $\mathrm{m}$ \\
\hline 17 & 4.1 & 34 & 89 & MCA inf & mid MCA & residual & $f$ \\
\hline 18 & 4.1 & 71 & 189 & TBI & temp/par & Broca & $f$ \\
\hline 19 & 4.1 & 43 & 43 & MCA inf & mid MCA & residual & $f$ \\
\hline 20 & 4.2 & 52 & 5 & $\mathrm{ICH}$ & front & residual & $\mathrm{m}$ \\
\hline 21 & 4.2 & 48 & 11 & MCA inf & ant MCA & residual & $f$ \\
\hline 22 & 4.3 & 32 & 41 & MCA inf & post MCA & unclassif & $\mathrm{m}$ \\
\hline 23 & 4.3 & 69 & 14 & MCA inf & ant MCA & anomic & $\mathrm{m}$ \\
\hline 24 & 4.5 & 46 & 25 & MCA inf & post MCA & anomic & $f$ \\
\hline 25 & 4.7 & 54 & 44 & MCA inf & ant MCA & residual & $f$ \\
\hline 26 & 4.8 & 44 & 44 & astro & temp & anomic & $\mathrm{m}$ \\
\hline 27 & 4.8 & 38 & 31 & glio & temp & residual & $f$ \\
\hline 28 & 5.4 & 60 & 124 & MCA inf & post MCA & residual & $\mathrm{m}$ \\
\hline 29 & 5.6 & 25 & 43 & TBI & front/temp & residual & $\mathrm{m}$ \\
\hline 30 & 6.2 & 59 & 88 & $S A H \rightarrow M C A$ inf & $\mathrm{mid} /$ post MCA & Broca & $\mathrm{f}$ \\
\hline 31 & 6.6 & 63 & 175 & MCA inf & ant MCA & Broca & $\mathrm{f}$ \\
\hline 32 & 7.7 & 48 & 55 & SAH $\rightarrow$ MCA inf & ant/post MCA & residual & $\mathrm{m}$ \\
\hline mean & 3.7 & 51.9 & 49.8 & & & & 17 ㅇ \\
\hline$S D$ & 1.57 & 11.7 & 50.6 & & & & $150^{\circ}$ \\
\hline
\end{tabular}

Supplementary Table ST1: The table provides size (diameter of sphere corresponding to lesion volume, DiaSph), age and months past onset (m.p.o.) of the disease leading to the brain lesion. Aetiologies, aphasia syndromes (according to Aachen Aphasia Test) and rough site of the lesions are provided; abbreviations are provided below.

aetiologies: 19 ischemic infarcts (isch); 7 intracerebral or subarachnoid haemorrhages (ICH/SAH); 3 traumatic brain injuries (TBI); 3 tumors stable after removal: meningioma (mening); 'Il astrocytoma (astro); glioblastoma (glio)

syndromes: 18 residual; 6 anomic; 3 Broca's; 3 no; 2 unclassifiable aphasias (all participants had an aphasia at disease onset)

site: anterior/ middle cerebral artery territory (ACA/MCA); anterior, middle or posterior part of MCA territory (ant/mid/post); frontal, temporal or parietal lobe (front/temp/par); basal ganglia, nucleus lentiformis; internal capsule; 